\title{
əInfluence of the Pacific Meridional Mode on ENSO Evolution and Predictability: Asymmetric Modulation and Ocean Preconditioning
}

\author{
Hanjie Fan, ${ }^{a}$ Bohua Huang, ${ }^{\mathrm{b}}$ Song YANG, ${ }^{\mathrm{a}, \mathrm{c}}$ AND WenJie Dong ${ }^{\mathrm{a}, \mathrm{c}}$ \\ ${ }^{\text {a }}$ School of Atmospheric Sciences and Guangdong Province Key Laboratory for Climate Change and Natural Disaster Studies, \\ Sun Yat-sen University, Zhuhai, China \\ ${ }^{\mathrm{b}}$ Department of Atmospheric, Oceanic and Earth Sciences and Center for Ocean-Land-Atmosphere Studies, \\ George Mason University, Fairfax, Virginia \\ ${ }^{\mathrm{c}}$ Southern Marine Science and Engineering Guangdong Laboratory (Zhuhai), Zhuhai, China
}

(Manuscript received 21 February 2020, in final form 30 September 2020)

\begin{abstract}
This study investigates the mechanisms behind the Pacific meridional mode (PMM) in influencing the development of El Niño-Southern Oscillation (ENSO) events and their seasonal predictability. To examine the relative importance of various factors that may modulate the efficiency of the PMM influence, a series of experiments is conducted for selected ENSO events with different intensity using the Community Earth System Model, in which ensemble predictions are made from slightly different ocean initial states but under a common prescribed PMM surface heat flux forcing. Overall, a PMM forcing matched to ENSO — that is, a positive or negative PMM prior to an El Niño or a La Niña, respectively—plays an enhancing role, whereas a mismatched PMM forcing plays a damping role. For the matched cases, a positive PMM event enhances an El Niño more strongly than a negative PMM event enhances a La Niña. This asymmetry in influencing ENSO largely originates from the asymmetry in intensity between the positive and negative PMM events in the tropics, which can be explained by the nonlinearity in the growth and equatorward propagation of the PMM-related anomalies of sea surface temperature (SST) and surface zonal wind through both wind-evaporation-SST feedback and summer deep convection response. Our model results also indicate that the PMM acts as a modulator rather than a trigger for the occurrence of ENSO event. Furthermore, the response of ENSO to an imposed PMM forcing is modulated by the preconditioning of the upper-ocean heat content, which provides the memory for the coupled low-frequency evolution in the tropical Pacific Ocean.
\end{abstract}

KEYWORDS: Climate variability; Interannual variability; Tropical variability

\section{Introduction}

The Pacific meridional mode (PMM) is an ocean-atmosphere covariation originating in the subtropics (Chiang and Vimont 2004; Amaya 2019). A positive PMM event is characterized by warm sea surface temperature (SST) anomalies and southwesterly surface wind anomalies extending from Baja California to the central-western equatorial Pacific, and vice versa for a negative PMM event (Alexander et al. 2010).

The PMM-related warm SST anomalies are first generated in the eastern subtropical Pacific by the reduced surface heat loss through a relaxation of climatological trade wind associated with the southward movement of the Asian-Pacific jet stream and Pacific storm track in the negative phase of the North Pacific Oscillation (NPO) (Walker and Bliss 1932; Rogers 1981; Linkin and Nigam 2008). ${ }^{1}$ These wind-induced

\footnotetext{
${ }^{1}$ The NPO is an atmospheric teleconnection pattern characterized by a meridional dipole in sea level pressure over the central Pacific Ocean, with opposite centers at approximately $35^{\circ}$ and $60^{\circ} \mathrm{N}$ (Kutzbach 1970; Wallace and Gutzler 1981).
}

¿ Denotes content that is immediately available upon publication as open access.

Corresponding author: Song Yang, yangsong3@mail.sysu.du.cn warm SST anomalies then excite westerly surface wind anomalies, especially on its southern flank, which in turn enhance the SST anomalies and expand southwestward by further reducing the latent heat loss (Vimont et al. 2003a,b). In this way, the SST and zonal surface wind anomalies propagate to the deep tropics via wind-evaporation-SST (WES) feedback (Xie and Philander 1994; Chang et al. 1997) and via changes in cloudiness, which alter the amount of surface shortwave radiation (Vimont et al. 2009).

The relationship between PMM and El Niño-Southern Oscillation (ENSO) has been discussed extensively in the past two decades (e.g., Amaya 2019). Chang et al. (2007) presented observational evidence that more than $70 \%$ of the ENSO events are preceded by PMM events, suggesting that the PMM plays an important role in connecting subtropical atmospheric variability and tropical ENSO events. Based on a coupled model analysis, Zhang et al. (2009) argued that the existence of the PMM is independent of ENSO, but the PMM can induce anomalous winds in the deep tropics, triggering oceanic waves to initiate ENSO events. Focusing on ENSO types, Yu et al. (2015) suggested that the strengthening of the PMM is likely the reason for the increasing occurrence of central Pacific-type El Niño events after 1990. In addition, the PMM is suggested to be a bridge that relays the interannual variations from the Atlantic to the tropical Pacific (Park et al. 2019).

Previous studies also demonstrated that the influence of the PMM on the development of ENSO possesses a seasonal phase-locking feature: PMM-related wind and SST anomalies 
in the boreal spring and summer can induce anomalous zonal surface winds over the central-western equatorial Pacific. This process, known as the "seasonal footprinting mechanism" (SFM; Vimont et al. 2001), can ultimately lead to the ENSO condition in the following winter. To analyze the thermodynamic processes in the SFM, Vimont et al. (2009) and Alexander et al. (2010) used the surface heat flux anomalies associated with the NPO to force coupled models, and examined the subsequent evolution of these initially forced ocean-atmosphere signals after the forcing was switched off. Their results reaffirmed that the SST anomalies induced by the NPO forcing continue to amplify and propagate to the tropics via the WES feedback, and that the seasonal-locking behavior of ENSO is to some extent related to the PMM.

Recently, another mechanism named "summer deep convection" (SDC) was recently proposed by Amaya et al. (2019) to connect the extratropical and tropical Pacific regions. By restoring SST anomalies in a coupled model to the observations in the North Pacific (north of $15^{\circ} \mathrm{N}$ ), the authors found that the mean ITCZ is sensitive to the PMM in the boreal summer and fall as it moves northward along its seasonal cycle. As a result, PMM-related SST anomalies can generate enhanced deep convection during these seasons, which produces Gill-like atmospheric circulation anomalies throughout the subtropical North Pacific. Such an atmospheric response directly results in zonal surface wind anomalies over the equator, which provides another pathway for the subtropical SST anomalies to influence the deep tropics.

Despite the documented importance of the PMM in the development of ENSO event, not every PMM event is followed by an ENSO event (Chang et al. 2007); we should further explore the factors that determine the effectiveness of PMM influence on the ENSO.

First, PMM events appear in different types, and it is unclear which PMM characteristics are the most favorable conditions for the SFM to effectively promote ENSO events. Park et al. (2013) conducted conditional composite analysis based on whether an El Niño event occurred or not after an NPO event had already occurred in the previous winter. They found that, for those NPO events not followed by ENSO events, the southern NPO lobe was more zonally elongated and farther extended toward the northeastern Pacific. As a result, the increased wind curl in the northeast promoted local ocean upwelling and the stronger wind speed caused larger net surface heat loss. Both factors cool the SST in the northeastern Pacific and are unfavorable for the SFM to affect ENSO events. It is also reported that after the mid-1990s, an eastward shift of the NPO's southern lobe causes a closer relationship with the ENSO in the following winter (Yeh et al. 2018).

Second, it is unclear whether the tropical ocean responds asymmetrically to the positive and negative PMM forcing. Recently, Thomas and Vimont (2016) demonstrated the nonlinear ENSO response to the PMM, showing a stronger SST response to positive forcing than to its negative counterpart. Conducting a series of sensitivity simulations using an atmospheric model [the Community Atmosphere Model (CAM)] coupled with a slab ocean and also using an intermediate coupled model (ICM), the authors demonstrated that ocean dynamics, primarily the nonlinear parameterization of subthermocline temperature within the ICM, dominated the asymmetry in the ENSO response to positive and negative PMM forcing. On the other hand, they suggested the evolutions of positive and negative PMM events themselves showed little asymmetry in the CAM-slab ocean model simulations.

Third, it is unclear to what extent the existing tropical ocean-atmospheric state and tendency determine the PMM influence on the ENSO. By nature, ENSO is a coupled tropical ocean-atmosphere phenomenon with major effects on equatorial ocean dynamics (Wyrtki 1985; Jin 1997; Meinen and McPhaden 2001; Anderson 2007). Previous studies pointed out that oceanic subsurface preconditioning could influence its response to zonal wind variation in general (Schopf and Harrison 1983; Busalacchi and Cane 1988; Dewitte et al. 2008; Capotondi and Sardeshmukh 2015). Since the PMM influences ENSO by inducing zonal surface wind anomalies in the tropical Pacific, the preexisting thermocline state, measured by the amplitude of anomalous upper-ocean heat content (HC) accumulated in the western tropical Pacific, may alter the efficiency of PMM-induced equatorial zonal wind anomalies in affecting the subsequent ENSO development because of its large thermal inertia and thus memory.

Previous studies have shed light on the importance of PMM for ENSO prediction. Examining ensemble spreads in seasonal hindcast experiments, Ma et al. (2017) suggested that PMMinduced perturbation is an important source of uncertainty in ENSO prediction from initial states during January-April. In a perfect-model experiment, Lu et al. (2017) showed that assimilating extratropical atmospheric "observations" (mostly PMMs) could reduce the error in predicting Niño-3.4 index by more than $40 \%$. A question to address is how to apply the knowledge of the PMM-ENSO relation to evaluate ENSO predictability more accurately and to improve the reliability of ENSO seasonal prediction. Larson and Kirtman (2014) investigated the potential for utilizing PMM variability as a supplemental tool for ENSO prediction within a climate prediction framework. However, these studies have not examined the specific effects of PMM on the prediction of individual ENSO events. In particular, it is of interest to further investigate the potential contributions of the factors described in the previous paragraph and to distinguish their relative roles in the perspective of prediction.

In this study, we conduct a series of sensitivity experiments using a coupled general circulation model to examine the influence of the PMM on the development and predictability of specific ENSO events, focusing on the relative roles of the factors that may modulate the efficiency of PMM influence on ENSO evolution. Four typical cases of strong and weak El Niño events and of strong and weak La Niña events are selected to conduct ensemble sensitivity simulations under prescribed positive and negative PMM forcing, respectively. Within such a framework, four factors are considered separately: 1) the forcing by positive and by negative PMM, 2) El Niño and La Niña events, 3) the amplifying or damping role of PMM on an evolving ENSO event, and 4) the roles of strong and weak $\mathrm{HC}$ preconditioning. Our experimental design is suitable for analyzing the sensitivity of PMM influence on 
ENSO because these experiments can isolate the respective effects of these factors.

This paper is organized as follows. In section 2, we describe the model used in this study and the experimental design. Overall results of the sensitivity experiments are presented in section 3. In section 4, we examine the impacts of typical PMM events on the evolution of ENSO events, focusing on the asymmetry of PMM forcing and ENSO responses (factors 1-3). In section 5, we demonstrate how oceanic precondition affects the efficiency of PMM forcing. A summary and discussion are presented in section 6 .

\section{Data and methods}

\section{a. Model description}

In this study, we use the Community Earth System Model (CESM) V1.2.2 from the National Center for Atmospheric Research to conduct several sensitivity experiments for ENSO prediction. The ocean component of the coupled system is the Parallel Ocean Program, version 2 (POP2), which has a horizontal resolution of approximately $1^{\circ}$ on a tripolar grid and vertically 60 levels with a maximum depth at $5375 \mathrm{~m}$. The atmospheric component is the CAM, version 4.0 (CAM4), with a horizontal resolution of $2^{\circ} \times 2^{\circ}$ approximately and 26 vertical levels.

We integrated the CESM for additional 50 years after a 250yr spinup run, which is used as the control simulation for this study. Throughout the 300 years of the simulation, the external greenhouse gas forcing is fixed at the level of year 2000. This CESM run reproduces ENSO with comparable spatial and temporal characteristics to those of the observations (Deser et al. 2012), in spite of an overestimated SST variability in the central-eastern Pacific Ocean as pointed out by previous studies (Hurrell et al. 2013).

Following Chang et al. (2007), we depict the PMM patterns by conducting a maximum covariance analysis (MCA) on the SST and surface wind anomalies for March-May (MAM; the peak season of PMM). Prior to calculating the MCA, ENSOrelated variability was removed by subtracting the linear regression of each variable on the cold tongue index (SST anomalies averaged over $\left.180^{\circ}-90^{\circ} \mathrm{W}, 6^{\circ} \mathrm{S}-6^{\circ} \mathrm{N}\right)$. Considering that the two time series of the first MCA mode are highly correlated, we define the PMM index as the time series associated with the SST pattern of the first MCA mode, and further obtain the PMM pattern by regression of both SST and surface wind anomalies on the PMM index. ${ }^{2}$ Figures $1 \mathrm{a}$ and $1 \mathrm{~b}$ show the simultaneous (MAM) PMM-related SST and surface wind anomalies in observations and simulation, respectively. The CESM-simulated PMM pattern displays similar spatial characteristics to the observations though with a bias of westward extension, which is a common systemic error in the present-day

\footnotetext{
${ }^{2}$ This procedure also guarantees that the PMM surface wind pattern is a linear function of the PMM SST pattern, although the left and right vectors of a singular value decomposition (i.e., MCA) mode generally do not satisfy this linear relationship (Newman and Sardeshmukh 1995).
}
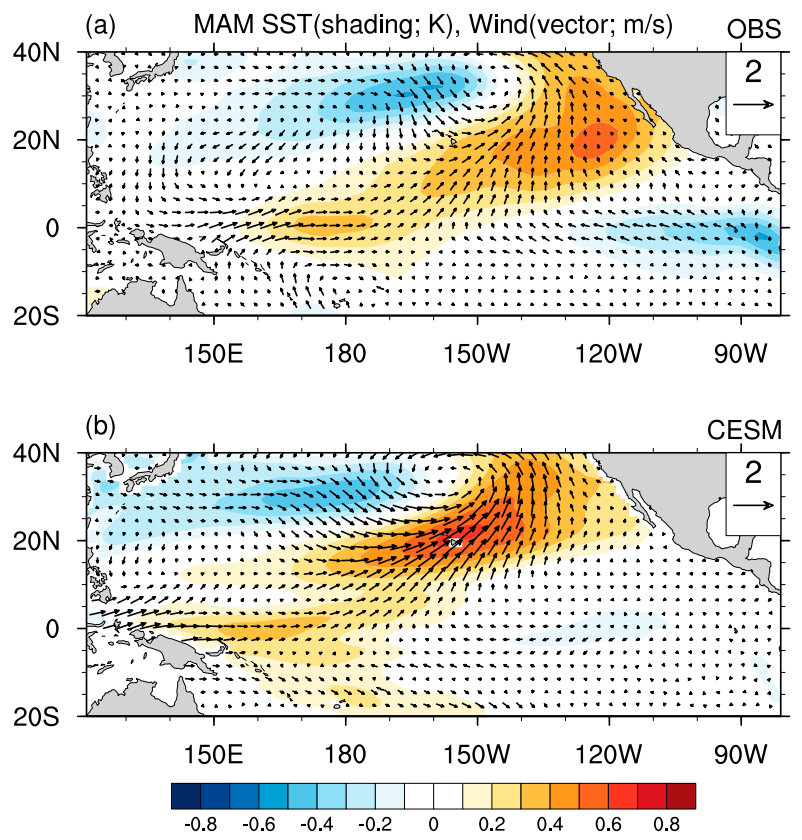

FIG. 1. PMM patterns of SST anomalies (shading; K) and surface wind anomalies (vector; $\mathrm{m} \mathrm{s}^{-1}$ ) in boreal spring (MAM) for (a) observations and (b) the CESM simulation. The vector scale of $2 \mathrm{~ms}^{-1}$ is given at the upper-right corner of each panel.

climate models (Lin et al. 2015). Figure 2 shows the monthly evolutions of surface latent heat flux and wind anomalies (left panels), along with SST anomalies (right panels), from January to May, which are also qualitatively similar to the observed (not shown), demonstrating a typical southward migration from the midlatitudes to the tropics via the WES feedback (Amaya 2019).

\section{b. Experimental design}

To examine the influence of a typical PMM event as depicted in Fig. 2 on the development of ENSO event, we conduct a series of prediction experiments in a perfect model framework, in which the PMM-related latent heat flux (Fig. 2) is imposed on the sea surface as an external forcing to the ocean component of the CESM. Four cases of strong and weak El Niño events and of strong and weak La Niña events are chosen from our 50-yr simulation: model years $257,295,254$, and 271 . They were selected according to the evolutions of SST, HC (Fig. 3), and Niño-3.4 index (solid black lines in Fig. 4) in the simulation, referred to as the "truth" hereinafter. Specifically, the socalled truth of case 257 is a tropical Pacific warming event with an amplitude of around $1.5^{\circ} \mathrm{C}$ (Fig. 4a), regarded as a strong El Niño case (SEN) for our study. Case 295 is a weak El Niño case (WEN) with a warming of about $0.5^{\circ} \mathrm{C}$ (Fig. $4 \mathrm{~b}$ ). On the other hand, cases 271 and 254 develop into a strong and weak La Niña events (SLN and WLN), respectively (Figs. 4c,d). The following procedure is applied to each of the cases.

First, a 10-member ensemble control predictability experiment (CTRL) is carried out without any external forcing but small random perturbations applied to the upper-level 
LHFLX (shading; W/m^2), Wind (vector; $\mathrm{m} / \mathrm{s}$ )

(a) Jan

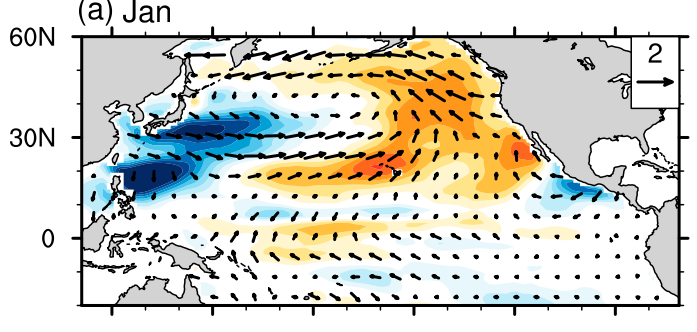

(c) Feb

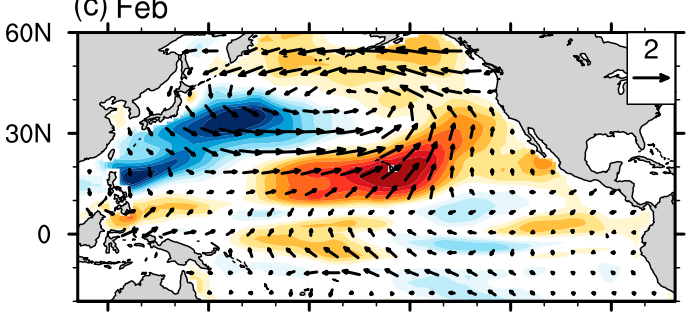

(e) Mar

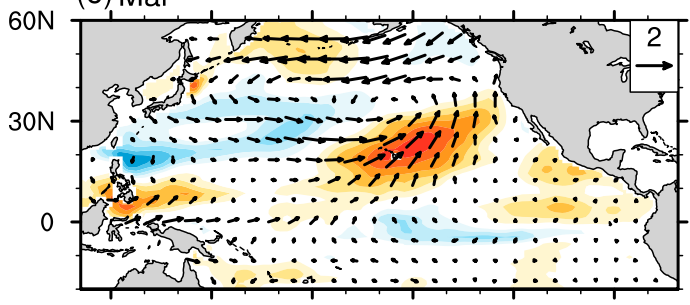

(g) Apr
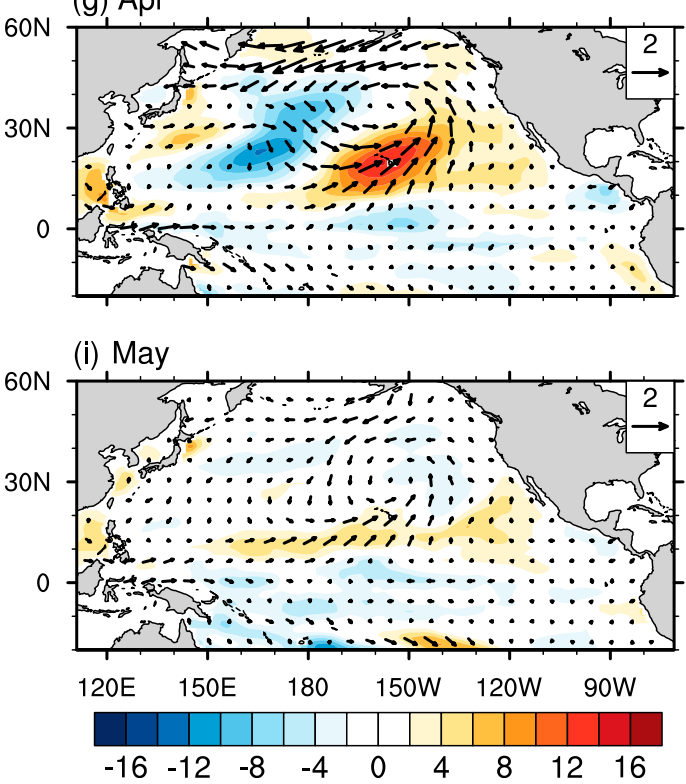

(b) Jan

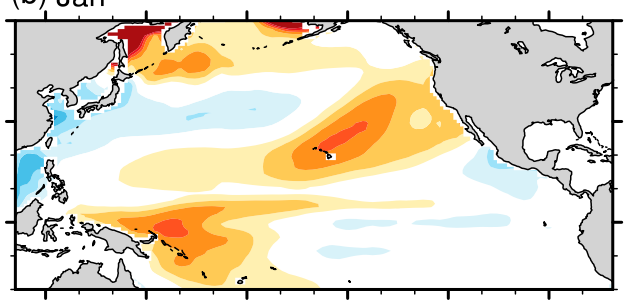

(d) Feb

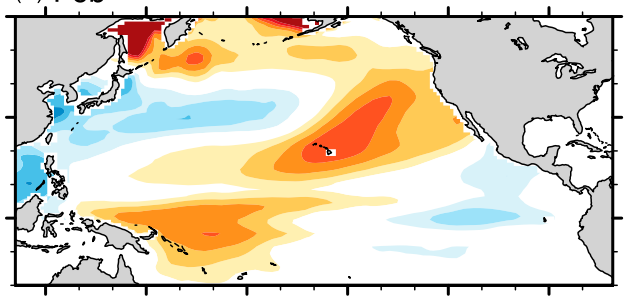

(f) Mar

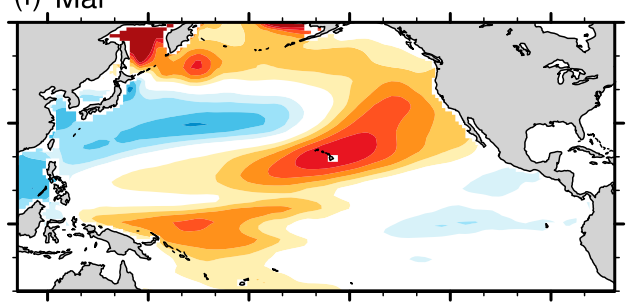

(h) Apr

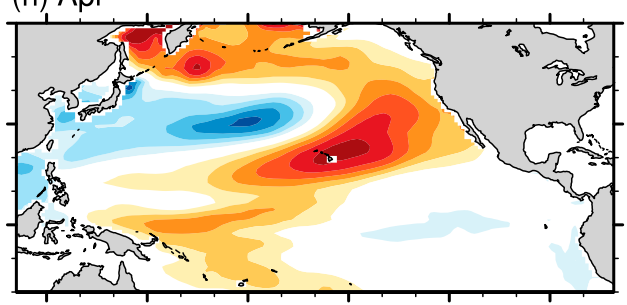

(j) May

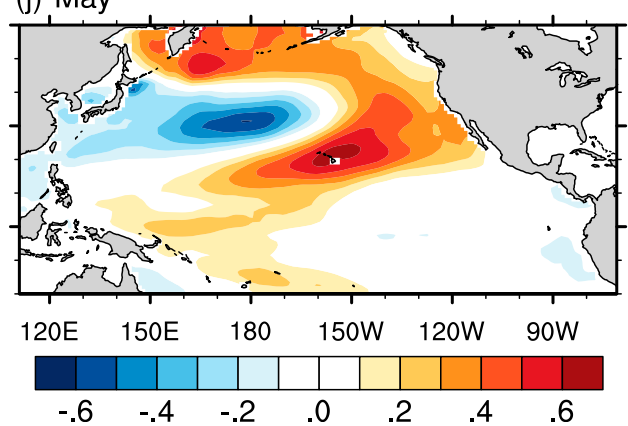

FIG. 2. Monthly evolution of simulated PMM-related (left) latent heat flux (shading; $\mathrm{W} \mathrm{m}^{-2}$ ) and surface wind (vector; $\mathrm{m} \mathrm{s}^{-1}$ ) and (right) SST (K) pattern for (a),(b) January; (c),(d) February; (e),(f) March; (g), (h) April; and (i),(j) May obtained by regressions of latent heat flux, surface wind, and SST anomalies on the PMM index for MAM. The shading scales for surface heat flux and SST anomalies are shown at the bottom of the figure. Positive values represent downward heat flux. The vector scale of $2 \mathrm{~m} \mathrm{~s}^{-1}$ is given at the upper-right corner of each panel. 
(a) SEN

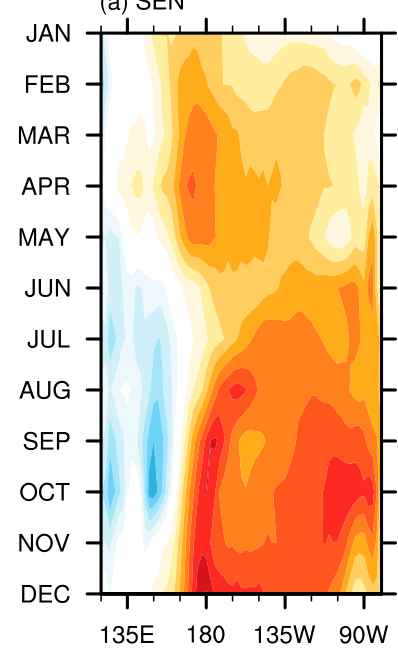

(b) WEN

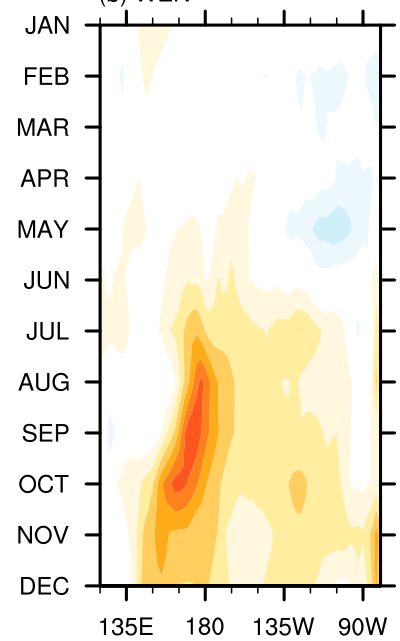

(c) WLN

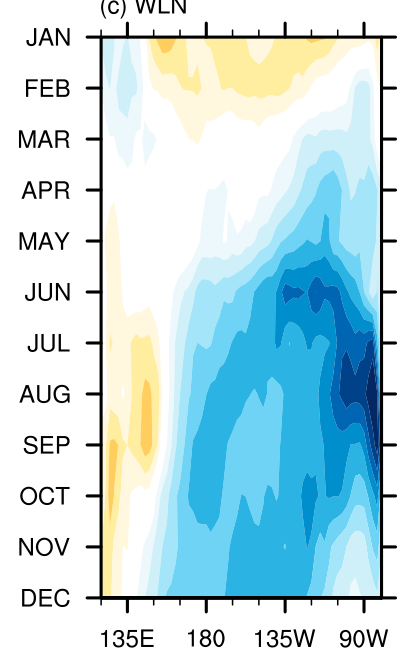

(d) SLN

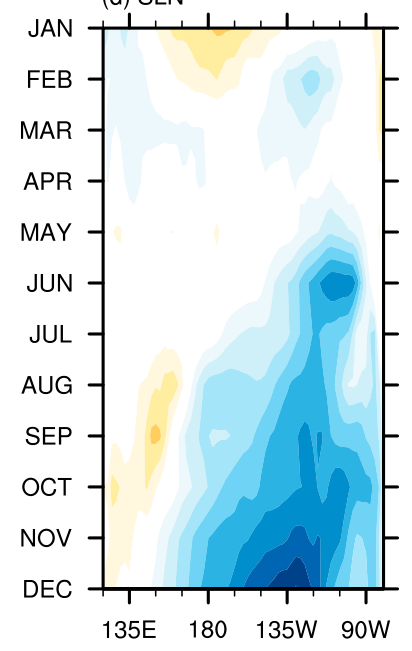

SSTA (K)

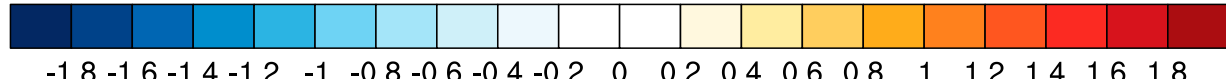

(e) SEN

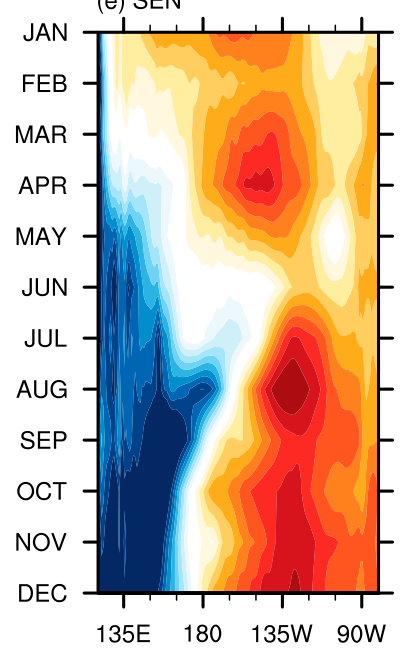

(f) WEN

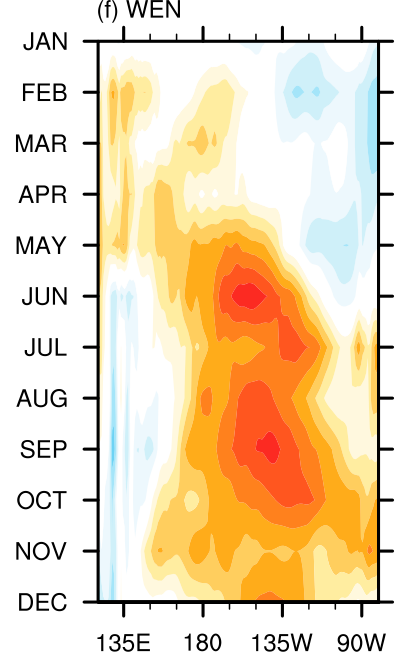

(g) WLN

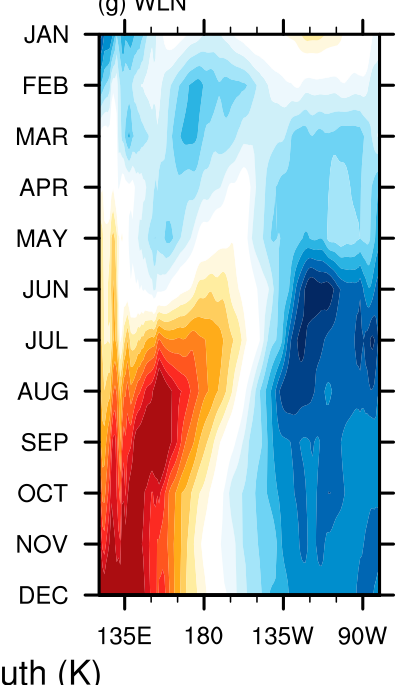

(h) SLN

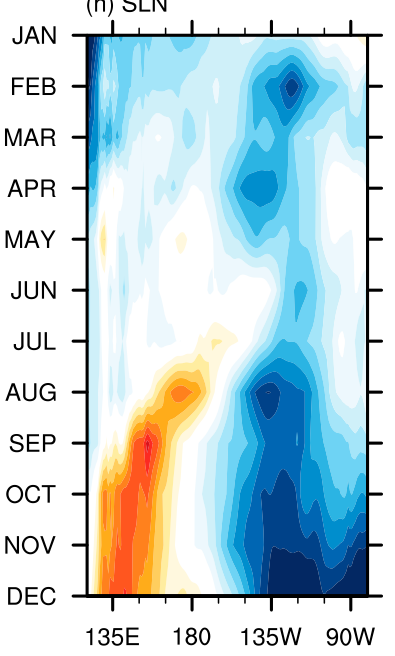

$\mathrm{HC}$ of Truth (K)

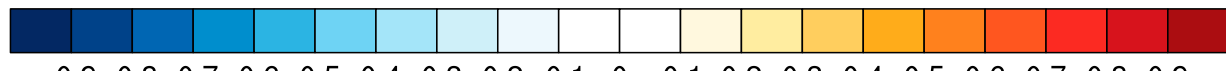

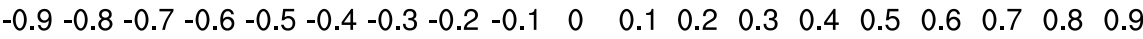

FIG. 3. Time-longitude section of monthly (top) SST anomalies and (bottom) upper-ocean heat content (HC; vertically averaged temperature in the upper $300 \mathrm{~m}$ of the ocean) over the equatorial Pacific $\left(5^{\circ} \mathrm{S}-5^{\circ} \mathrm{N}\right)$ in the truth of (a), (e) SEN; (b), (f) WEN; (c), (g) WLN; and (d),(h) SLN. The shading scales for SST and HC anomalies (K) are shown at the bottom of the top and bottom panels, respectively.

temperature of the atmospheric initial conditions taken from the restart files of the long simulation. These runs evaluate the predictability of the respective ENSO events and serve as the baseline for demonstrating the influence of PMM from sensitivity experiments. Each control run is integrated for one year, starting from 1 January. The spread of the Niño-3.4 of the ensemble members in CTRL (dashed gray lines and gray shading in Fig. 4) exhibits substantial differences among the members for all four cases. However, the ensemble means of CTRL (solid color lines in Fig. 4) generally capture the typical amplitude during the mature phase in the truth except for WLN, with the ensemble mean underestimating the cold SST anomalies (Fig. 4c).

Next, we add the PMM-related forcing to the CESM over the Pacific from $20^{\circ} \mathrm{S}$ to $60^{\circ} \mathrm{N}$ in a set of sensitivity runs (hereinafter referred to as FLUX). To be comparable with CTRL, 10-member ensemble runs of FLUX are conducted with the same initial conditions as CTRL. In this set of experiments, the monthly PMM-related heat fluxes (shading in the left panels of Fig. 2) are first linearly interpolated to daily 
(a) SEN

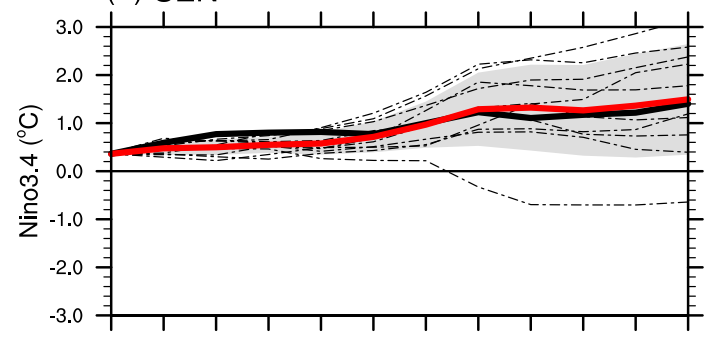

(c) WLN

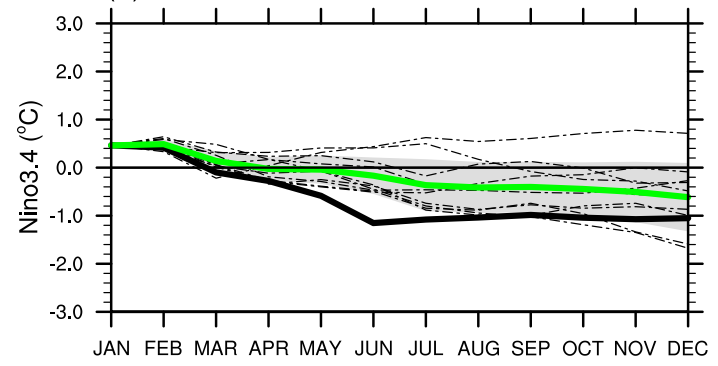

(b) WEN

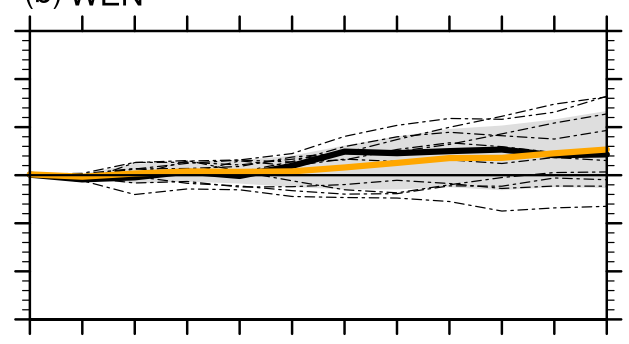

(d) SLN

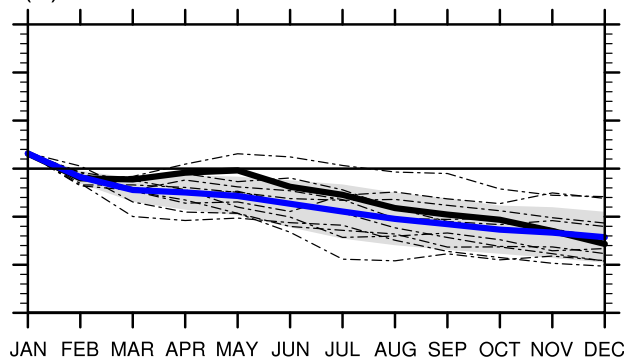

FIG. 4. Time series of monthly Niño-3.4 index $\left({ }^{\circ} \mathrm{C}\right)$ in CTRL of (a) SEN, (b) WEN, (c) WLN, and (d) SLN. Ensemble members are shown as gray dashed lines, ensemble means are given by solid color lines, and standard deviations of the ensemble spread are indicated by gray shading. The thick black line shows the truth from the original simulation.

values. To enlarge the response in the sensitivity runs, the imposed forcing is multiplied by 3 from the values in Fig. 2. Each of the CESM runs is then forced by the enlarged daily forcing at every time step from 1 January to 15 May, and integrated freely afterward to the end of the year. For each selected case, two ensemble simulations are carried out with positive and negative PMM forcing to represent different phases of PMM events, respectively (hereinafter + PMM and -PMM).

Note that prior to imposing the PMM-related forcing, naturally occurring PMM conditions might already exist in the CTRL runs. In particular, positive PMM conditions occur during spring and summer in the CTRL ensemble mean of SEN (Figs. 5a,b). Therefore, there is a possibility that these naturally occurring PMMs in the ensemble members might interfere with the prescribed PMM forcings in the FLUX runs and modify the model responses. For instance, the prescribed forcings might not generate a full positive or negative PMM response in the FLUX runs. However, with our modeling framework, we are able to diagnose the possible differences in the PMM-related processes between positive and negative PMM forcings using the CTRL ensemble mean as the baseline. In this case, even though the PMM forcing in mismatched cases (positive PMM for La Niña or negative PMM for El Niño) might not trigger a full PMM response, the relative influences to the evolutions of the ENSO events, provoked by the corresponding positive and negative feedbacks in the tropical and equatorial region, can still be evaluated objectively.

Note that the response of subtropical SST to the (3 times) enlarged PMM forcing (Figs. 5i,j) is about one-half of the strongest PMM event in 2015 (see Fig. 12e in Amaya et al. 2019). Table 1 summarizes the combinations of FLUX experiments and corresponding figures for the concerned variables (four factors given in the introduction) in this study.

\section{Overall responses to PMM-related heat flux}

As an example, Fig. 6 shows the ensemble-mean SST and surface wind anomalies in experiments + PMM, and the differences from CTRL, for SEN. While the SST and surface wind anomalies in CTRL (and the truth; not shown) feature a moderate El Niño event in winter (left panels, Fig. 5), + PMM drives it to become a strong eastern Pacific (EP; Kao and $\mathrm{Yu}$ 2009) El Niño event by the end of the year (left panels, Fig. 6). The EP-type pattern here seems to contradict some previous studies, which suggests that the PMM contributes to the central Pacific (CP) ENSO event (e.g., Wang et al. 2019). However, this PMM-CP ENSO relationship should be the situation when the equatorial Pacific is not strongly preconditioned by anomalous subsurface HC.

For the differences between + PMM and CTRL (right panels, Fig. 6), the contrast originates in the northern subtropical Pacific during January-February (JF; Fig. 6e) and grows to distinct PMM SST and surface wind anomalous patterns in MAM (Fig. 6f), showing the effect of imposed heat flux forcing. More important, although the differences in the equatorial zonal wind are generally weak during JanuaryMay (JFMAM), the positive differences (i.e., stronger westerly wind in +PMM than in CTRL) enlarge and persist during June-September (JJAS; Fig. 6g) and October-December (OND; Fig. 6h), well after the +PMM forcing is terminated. It is clear that the + PMM forcing triggers strong air-sea feedback in the equatorial Pacific, leading to stronger westerly anomalies. Correspondingly, the warming amplitude over the tropical 


\section{CTRL SST(shading; K), UV(vector; m/s)}
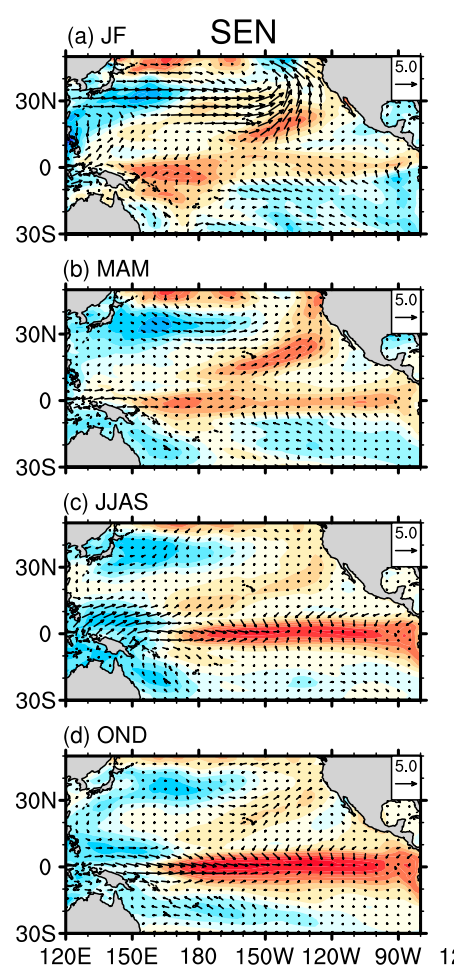
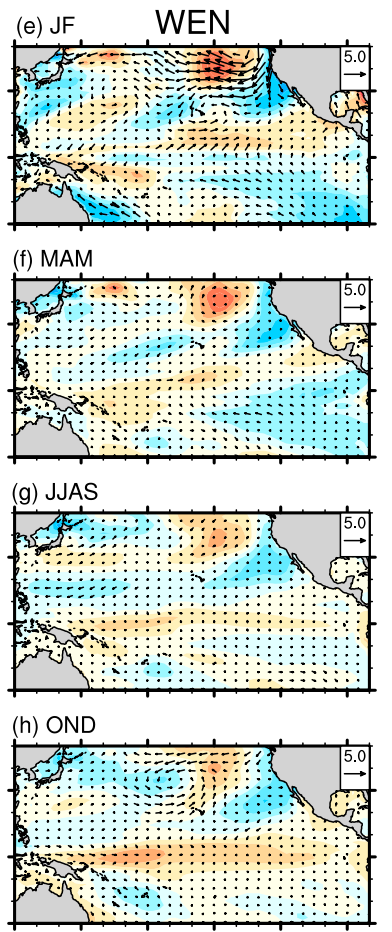
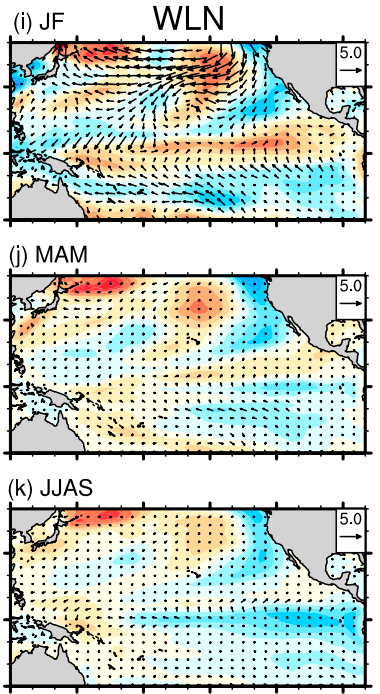

(I) OND

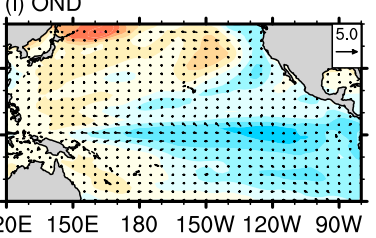

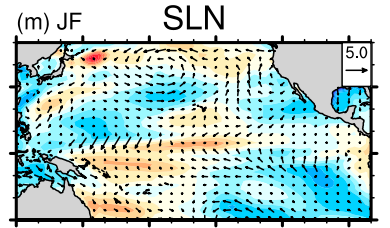
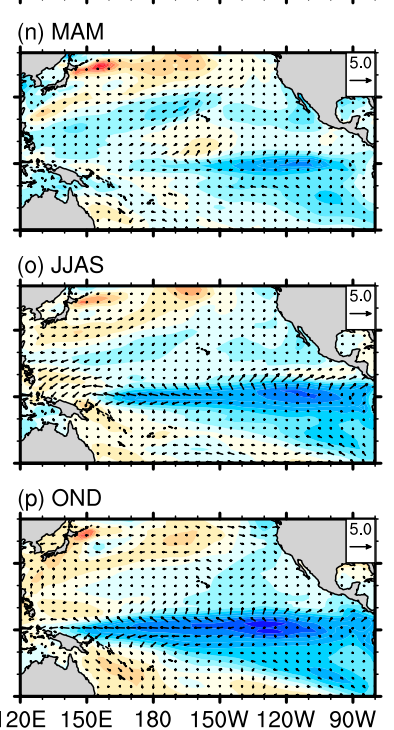

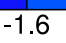

FIG. 5. Seasonal evolution of ensemble-mean SST anomalies (shading; K) and surface wind anomalies (vector; $\mathrm{m} \mathrm{s}^{-1}$ ) for in the CTRL of (a)-(d) SEN, (e)-(h) WEN, (i)-(l) WLN, and (m)-(p) SLN. The reference vector of $5 \mathrm{~m} \mathrm{~s}^{-1}$ is shown at the upper-right corner of each panel.

Pacific becomes much stronger in + PMM (Figs. 6c,d), clearly demonstrating the amplification influence of the positive PMM events on the development of El Niño event.

Figure 7 shows the time series of the Niño-3.4 index of all sensitivity runs for the four cases, including the ensemble means (solid color lines) and ensemble members (dashed color lines) for the +PMM (red) and - PMM (blue) accompanied with the CTRL ensemble means (solid black lines). We can see that positive PMM forcing enhances El Niño events but damps La Niña events. Negative PMM forcing plays an opposite role in affecting the development of ENSO events, but with a noticeably weaker influence. Surprisingly, the -PMM forcing seems to cause little enhancement to the ensemble-mean prediction of the La Niña events (Figs. 7c,d). There may also exist a difference between PMM influences on El Niño and La Niña events; that is, the effect of PMM is more symmetric for the El Niño events than for the La Niña events. Several questions can then be raised from these asymmetries. Why does the influence of PMM on the development of ENSO display asymmetry between the positive and negative phases of

TABLE 1. Summary of combinations of FLUX experiments and corresponding figures for concerned variables.

\begin{tabular}{|c|c|c|}
\hline Variable & Combination & Figure \\
\hline $\begin{array}{l}+\mathrm{PMM} \text { vs } \\
\quad-\mathrm{PMM}\end{array}$ & $\begin{array}{l}+ \text { PMM and El Niño vs } \\
- \text { PMM and El Niño }\end{array}$ & $\begin{array}{l}\text { Left in Fig. } 8 \text { vs } \\
\text { right in Fig. } 8\end{array}$ \\
\hline $\begin{array}{l}\text { El Niño vs } \\
\text { La Niña }\end{array}$ & $\begin{array}{l}+ \text { PMM and El Niño and - PMM and El Niño } \\
\text { vs }+ \text { PMM and La Niña and - PMM and La Niña }\end{array}$ & $\begin{array}{l}\text { Red lines in Fig. } 12 \\
\text { vs blue lines in Fig. } 12\end{array}$ \\
\hline $\begin{array}{r}\text { Amplification } \\
\text { vs damping }\end{array}$ & $\begin{array}{l}+ \text { PMM and El Niño and }- \text { PMM and La Niña } \\
\text { vs }- \text { PMM and El Niño and }+ \text { PMM and La Niña }\end{array}$ & Solid lines in Fig. 12 vs dashed lines in Fig. 12 \\
\hline $\begin{array}{l}\text { Strong-HC vs } \\
\text { weak-HC }\end{array}$ & $\begin{array}{l}\text { PMM and Strong-HC (El Niño/La Niña) vs PMM and } \\
\text { Weak-HC (El Niño/La Niña) }\end{array}$ & Left in Fig. 14 vs right in Fig. 14 \\
\hline
\end{tabular}




\section{SEN SST(shading; K), UV(vector; m/s)}
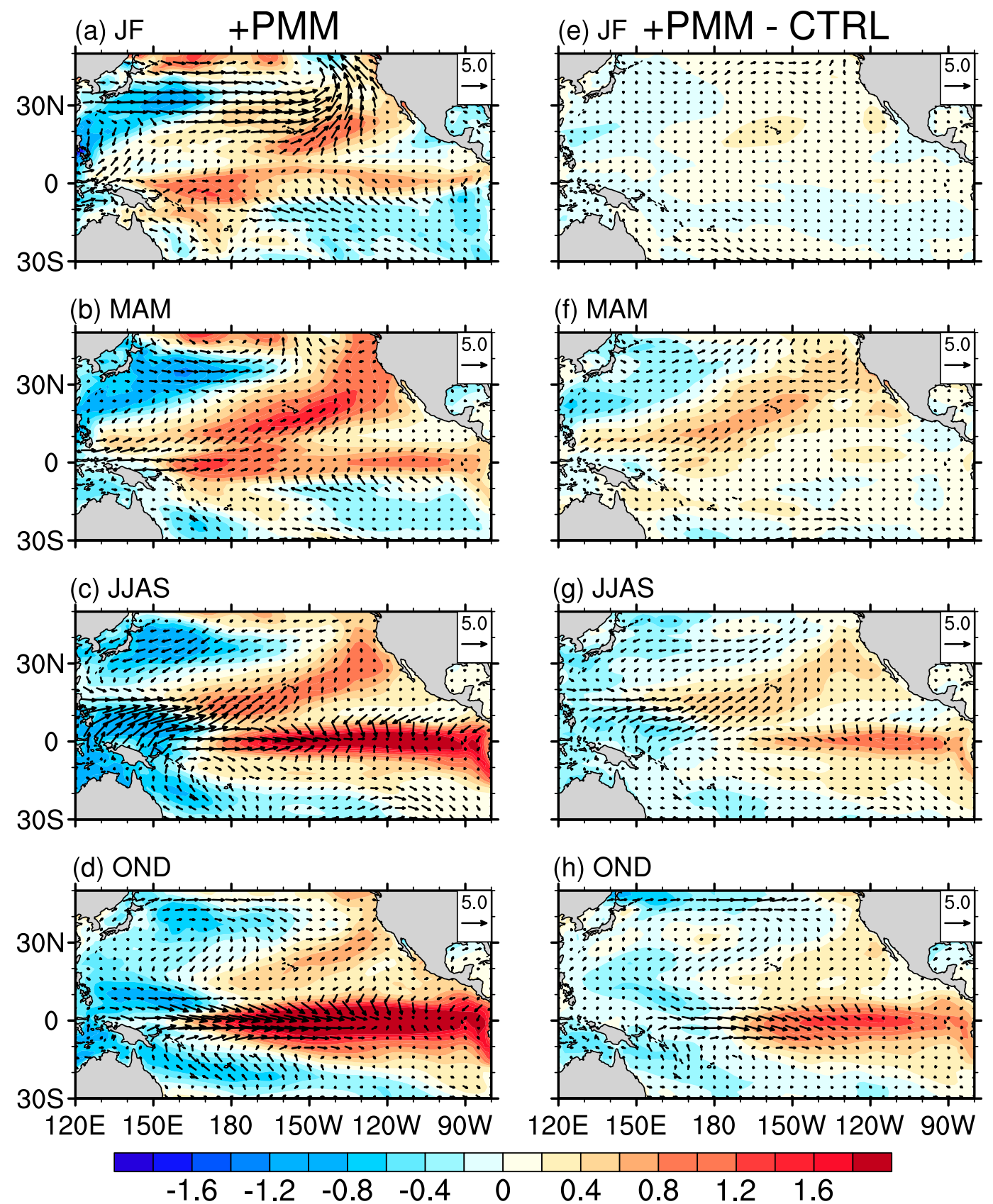

FIG. 6. Seasonal evolution of ensemble-mean SST anomalies (shading; K) and surface wind anomalies (vector; $\mathrm{m} \mathrm{s}^{-1}$ ) for (a)-(d) + PMM and and (right) the difference + PMM minus CTRL in SEN. The reference vector of $5 \mathrm{~m} \mathrm{~s}^{-1}$ is shown at the upper-right corner of each panel.

PMM? How does the asymmetry affect ENSO predictability? Furthermore, it seems that the response of ENSO to PMM shows different amplitudes between the cases with large $\mathrm{HC}$ and those with relatively smaller HC (comparing Figs. 3e, h to Figs. 3f,g and comparing Figs. 7a,d to Figs. 7b,c). In the following, we will answer these questions by examining relevant physical mechanisms.

\section{Asymmetric influence of PMM on ENSO}

a. Asymmetry of PMM forcing

Figure 8 shows the responses of SST, SLP, and surface winds to the imposed heat flux forcing of positive and negative PMM, respectively, based on the average of two El Niño cases. Similar to the seasonal evolution shown in Figs. $6 \mathrm{e}$ and $6 \mathrm{f}$, the 
(a) SEN

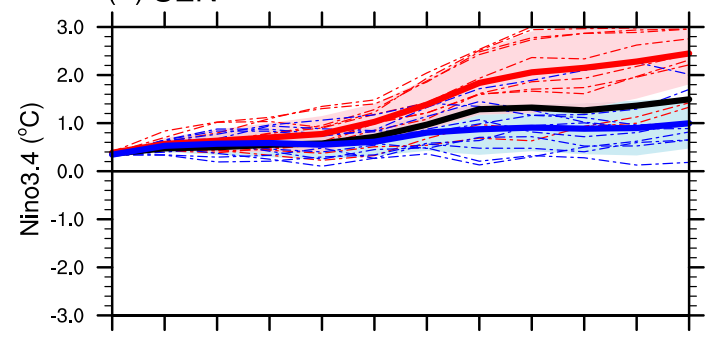

(c) WLN

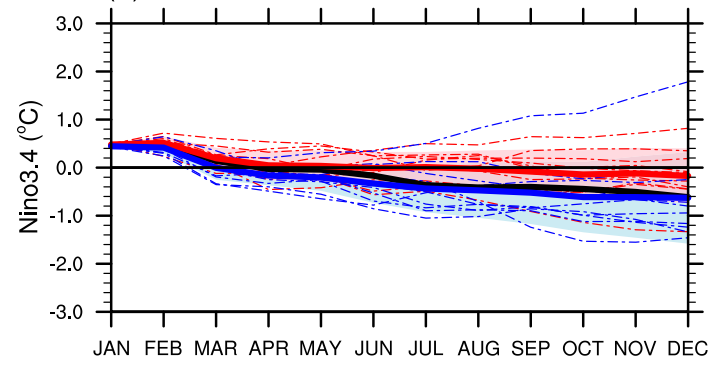

(b) WEN

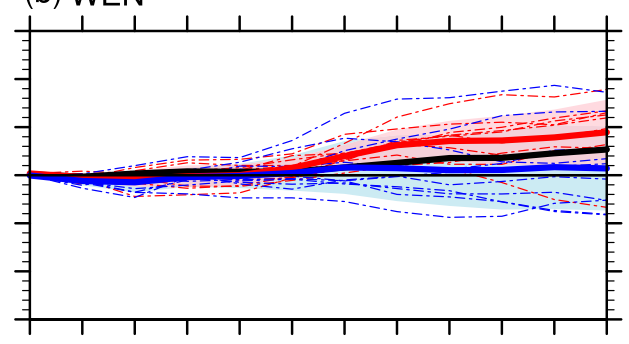

(d) SLN

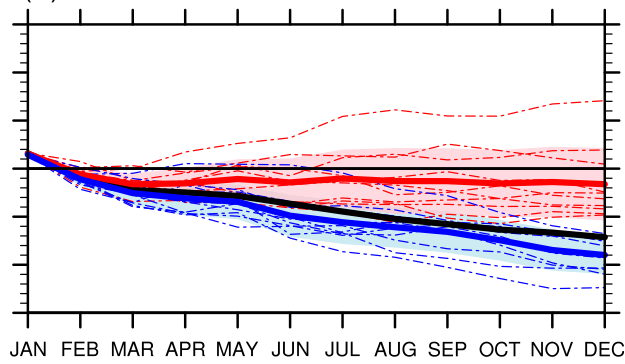

FIG. 7. Time series of monthly Niño-3.4 index $\left({ }^{\circ} \mathrm{C}\right.$ ) of (a) SEN, (b) WEN, (c) WLN, and (d) SLN. The thick black line is the ensemble mean of CTRL, and solid red and blue lines are the ensemble means of + PMM and - PMM, respectively. The ensemble members in FLUX are shown by the thin dashed red (positive) or blue (negative) lines, and the blue and red shadings indicate their corresponding standard deviations, respectively.

El Niño-averaged responses to + PMM first emerge as an area of positive SST difference in the northern central Pacific during January-March (JFM; shading, Fig. 8a), which is directly forced by the prescribed positive surface heat flux shown in left panels of Fig. 2. The subtropical SST anomalies cause a southward extension of the negative SLP anomalies (contours; Fig. 8a), which tightens the regional SLP gradient (Lindzen and Nigam 1987) and induces weak southwesterly wind anomalies (vectors; Fig. 8a). Note that the southwesterly wind anomalies are superimposed on the climatological northeasterly trade wind, and thus reduce the total wind speed and evaporative heat loss from the sea surface. As a result, the surface wind anomalies overlie the SST anomalies and enhance the existing SST anomalies through the WES feedback (Xie and Philander 1994). By April-June (AMJ), a low SLP center develops in the subtropical central Pacific, with intense southwesterly wind and warm SST anomalies on its southern flank (Fig. 8b). This air-sea spatial structure not only promotes further intensification of the coupled anomalies but also causes their equatorward propagation because the warm SST anomalies extend the low SLP center southward while the consequent wind change on its southern flank also generates new SST anomalies in the south (e.g., Huang and Shukla 2005).

After the imposed PMM forcing is terminated on 15 May, the coupled patterns of SST, SLP, and surface winds continue to grow and expand equatorward through the WES feedback (AMJ; Fig. 8b). Moreover, the SST and surface wind anomalies in + PMM further extend to the northwestern tropical Pacific. Once the westerly anomalies propagate to the equatorial Pacific, they evoke dynamic processes including oceanic downwelling
Kelvin waves and anomalous eastward zonal advection. These processes induce SST warming over the central and eastern equatorial Pacific in the following seasons (Fig. 8c) and modulate the amplitude of ENSO event. Moreover, significant westerly anomalies emerge from the central equatorial Pacific during July-September (JAS), resembling the behavior of the SDC response proposed by Amaya et al. (2019). Recall that the SDC response is a Gill-type atmospheric response associated with offequatorial deep convection in the boreal summer and fall when the ITCZ moves northward, which provides another mechanism for the extratropical Pacific to influence ENSO variability. In winter, an El Niño-like SST change appears with westerly anomalies prevailing over the equator (Fig. 8d).

The responses in - PMM are analogous to those in + PMM albeit of an opposite sign. However, the responses in - PMM are weaker than those in + PMM from the extratropical to tropical Pacific although they are forced by the heat flux with equal amplitude (of opposite sign). Especially in the mature season of ENSO event (OND; Figs. 8d,h), +PMM induces significant positive SST anomalies in the equatorial Pacific whereas no significant response to $-\mathrm{PMM}$ is seen over the tropics.

Figure 9 displays the same results as Fig. 8, but based on the average of two La Niña cases. In comparison, the responses spanning between the subtropical and equatorial Pacific show similar asymmetry; that is, the influence of + PMM is stronger than that of - PMM. These nonlinear results in both El Niño and La Niña cases indicate an asymmetry in the developments between positive PMM and negative PMM and in their influences on the ENSO. In the following, the mechanisms for the asymmetry between +PMM and - PMM are 


\section{EN SLP(contour: $\mathrm{hPa}$ ), SST(shading: $\mathrm{K}$ ), UV(vector: $\mathrm{m} / \mathrm{s}$ )}

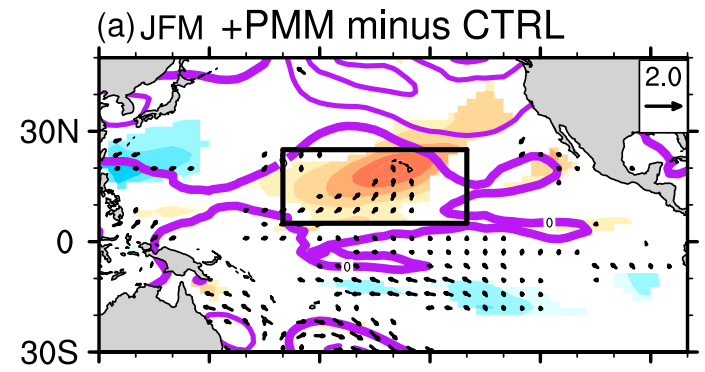

(b) AMJ

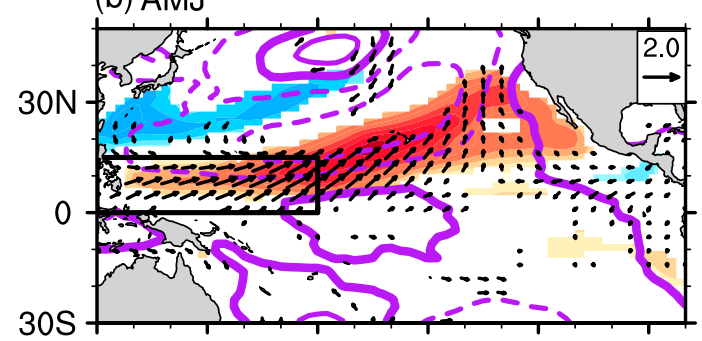

\section{(c) JAS}

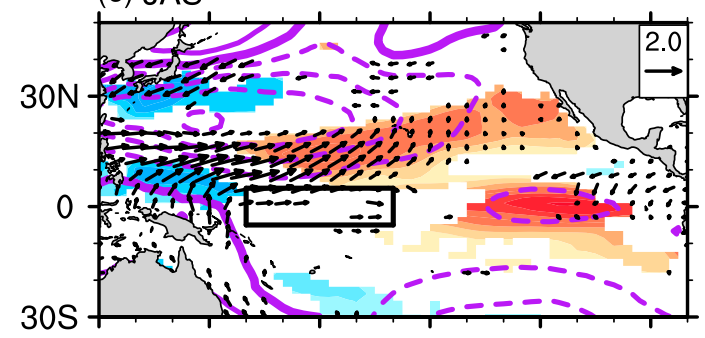

(d) OND

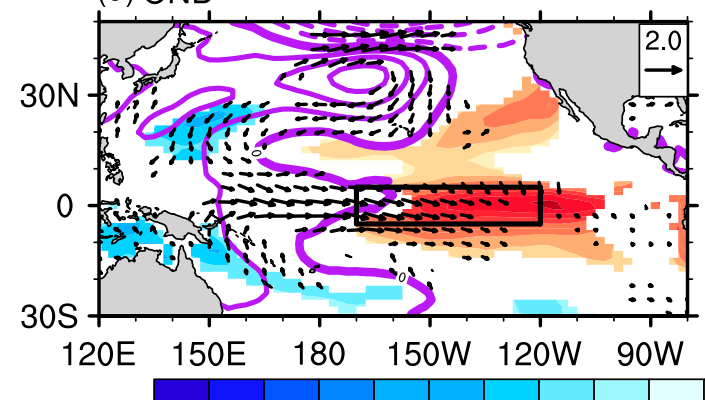

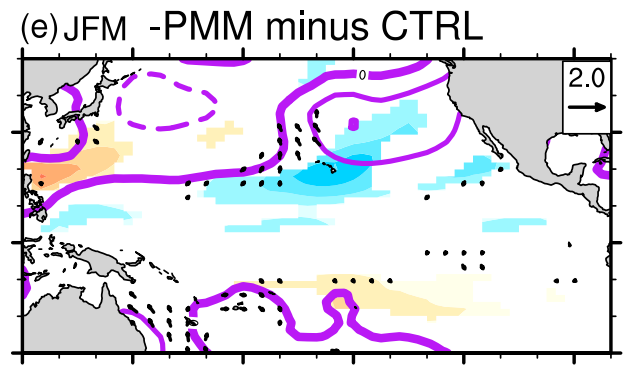

(f) $\mathrm{AMJ}$

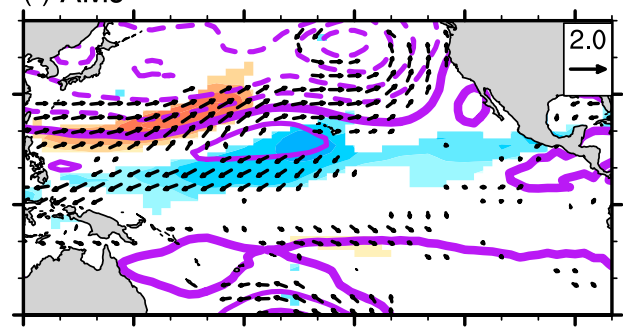

(g) JAS

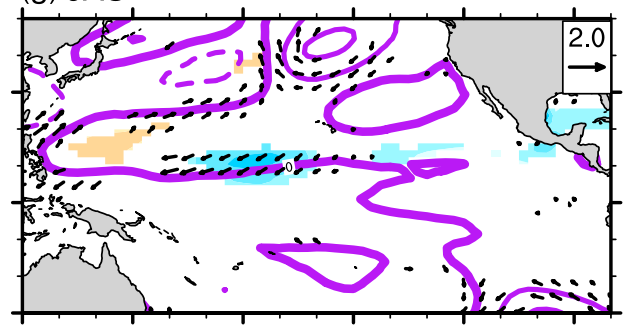

(h) OND

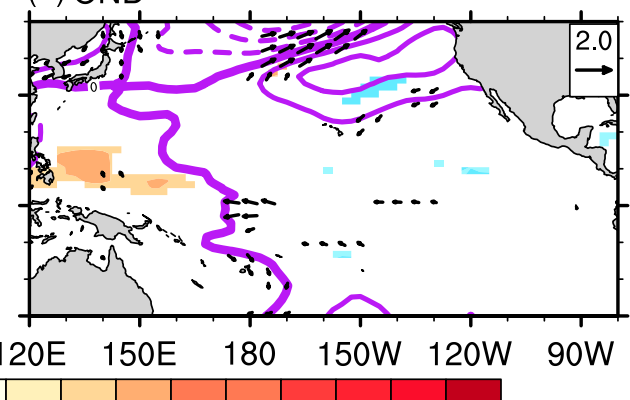

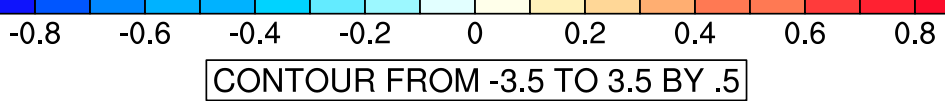

FIG. 8. Seasonal evolution of the responses of SLP (contours; hPa), SST (shading; K), and surface wind (vectors; $\mathrm{m} \mathrm{s}^{-1}$ ) to the PMM-related forcing based on the average of two El Niño cases (a)-(d) for + PMM minus CTRL and (e)-(h) for - PMM minus CTRL for (top) JFM, (top middle) AMJ, (bottom middle) JAS, and (bottom) OND. The reference vector of $3 \mathrm{~m} \mathrm{~s}^{-1}$ is shown at the upper-right corner of each panel. SST and surface wind are shown only when statistically significant at the $95 \%$ confidence level as based on Student's $t$ test.

demonstrated using the four-case-averaged composite to show a general result.

\section{1) WES FEEDBACK}

Monthly indices are used to quantify the asymmetric characteristics for + PMM and - PMM forcing, respectively. First,
Fig. 10a displays the response of the northern central Pacific (NCP) SST index (averaged over $170^{\circ} \mathrm{E}-140^{\circ} \mathrm{W}, 5^{\circ}-25^{\circ} \mathrm{N}$; black-outlined box in Fig. 8a), showing the growth of the PMM extratropical SST anomalies. In Fig. 10a, the warming amplitude of the NCP index in + PMM is greater than the cooling amplitude in -PMM in May when the index peaks, 


\section{LN SLP(contour: $\mathrm{hPa}$ ), SST(shading: $\mathrm{K}$ ), UV(vector: $\mathrm{m} / \mathrm{s}$ )}
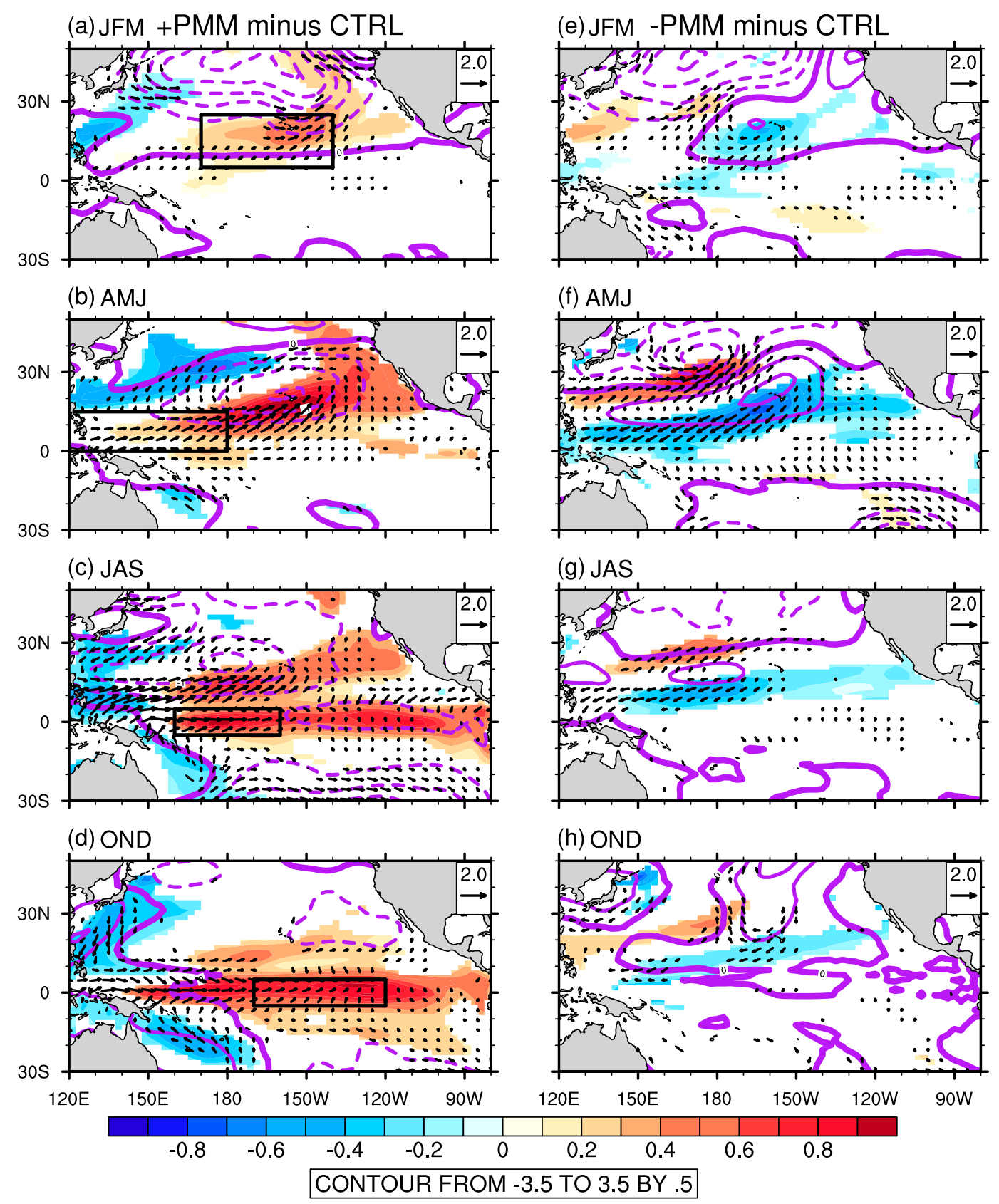

FIG. 9. As in Fig. 8, but for the average of two La Niña cases.

implying that an asymmetry exists in the coupled response since the imposed forcing is of same intensity in + PMM and -PMM. More evidence for the stronger WES feedback is the growing and eventually stronger zonal surface wind anomalies over the northwestern tropical Pacific (NWTP $; 20^{\circ} \mathrm{E}-180^{\circ}, 0^{\circ}-15^{\circ} \mathrm{N}$; black-outlined box in Fig. $8 \mathrm{~b}$ ) during summer and autumn in + PMM (red curve in Fig. 10b), while the winds are largely sustained in their spring level in $-\mathrm{PMM}$.
The contribution of wind speed and moisture content to SST change is given by the bulk formula of latent heat flux (Vimont et al. 2009):

$$
\mathrm{LH}=-L_{v} C_{e} \rho_{a} \times \nabla q \times \bar{w}
$$

where $L_{v}$ is the latent heat of vaporization $\left(2.5 \times 10^{6} \mathrm{~J} \mathrm{~kg}^{-1}\right)$, $C_{e}$ is an aerodynamic transfer coefficient [we use a constant value of 1023 as in Vimont et al. (2009)], and $\rho_{a}$ is the air 
(a) SST (NCP)

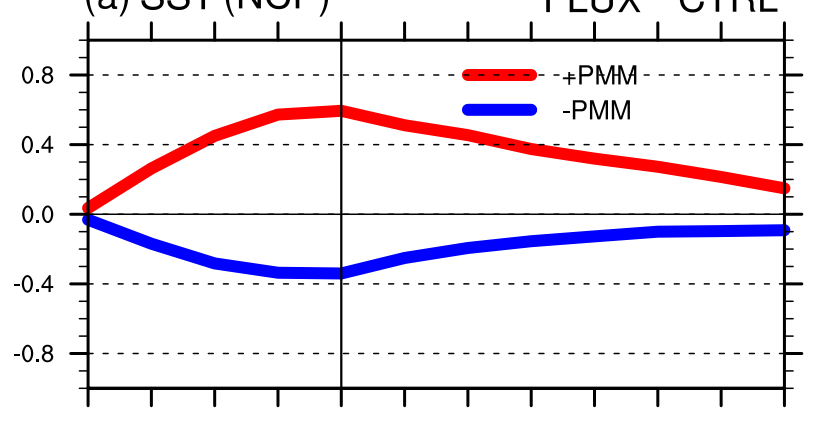

JAN FEB MAR APR MAY JUN JUL AUG SEP OCT NOV DEC (b) U (NWTP)

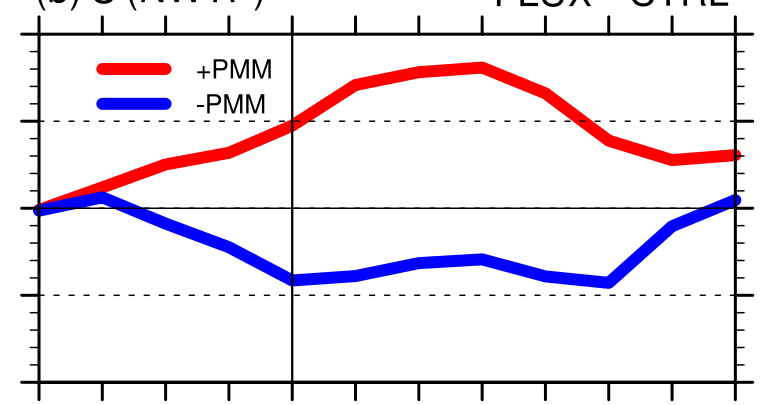

JAN FEB MAR APR MAY JUN JUL AUG SEP OCT NOV DEC

\section{$\mathrm{dLH} / \mathrm{dU}$ (shading: $\mathrm{W}^{*} \mathrm{~m}-2 / \mathrm{m}^{*} \mathrm{~s}-1$ )}
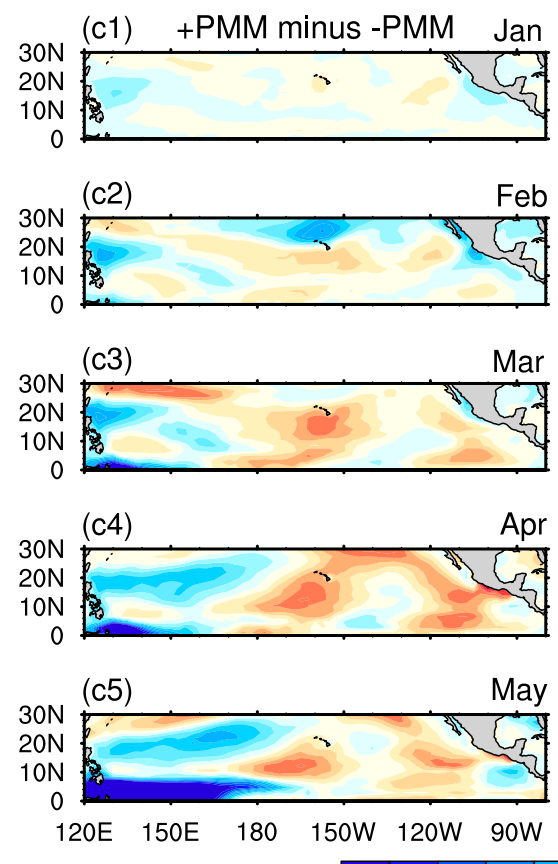

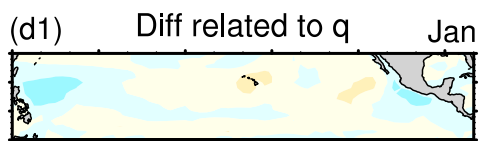

(d2)

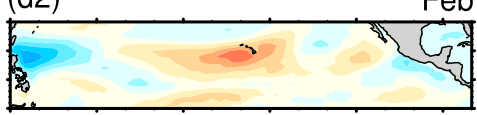

(d3)

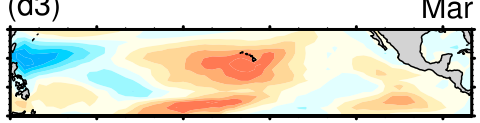

(d4)

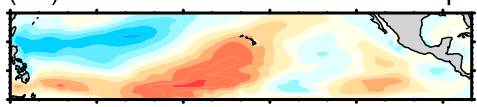

(d5)

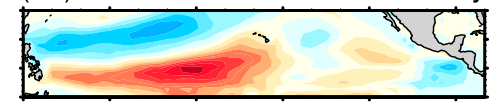

120E 150E 180 150W 120W 90W

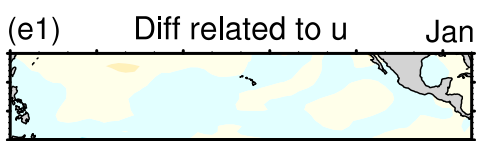

(e2)
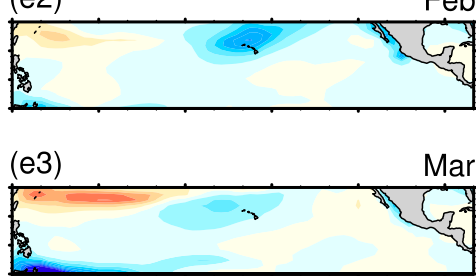

(e4)

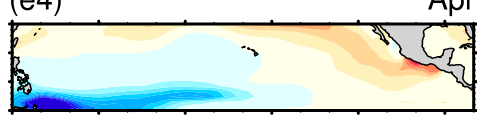

(e5)

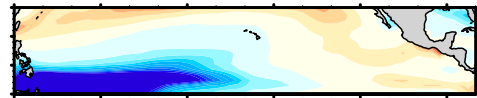

120E 150E 180 150W 120W 90W

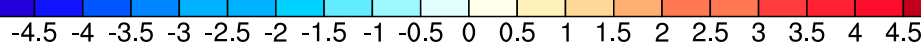

FIG. 10. The responses (+PMM/-PMM minus CTRL) of monthly (a) NCP $\left(170^{\circ} \mathrm{E}-140^{\circ} \mathrm{W}, 5^{\circ}-25^{\circ} \mathrm{N}\right.$; black-outlined box in Fig. 8 a) SST index and (b) NWTP $\left(120^{\circ} \mathrm{E}-180^{\circ}, 0^{\circ}-15^{\circ} \mathrm{N}\right.$; black-outlined box in Fig. $\left.8 \mathrm{~b}\right)$ zonal wind index. The red line is the averaged result of $+\mathrm{PMM}$, and the blue line is the averaged result of -PMM. Also shown is the difference in monthly transient latent heat flux sensitivity to the changes in zonal surface wind $(\partial \mathrm{LH} / \partial U$ ) between + PMM and - PMM (+PMM minus - PMM) for (c1),(d1),(e1) January; (c2),(d2),(e2) February; (c3),(d3),(e3) March; (c4),(d4),(e4) April; and (c5),(d5),(e5) May: (left) the total difference, (center) the difference related to the contrast of vertical humidity gradient, and (right) the difference related to the contrast of zonal winds. Positive value represents stronger sensitivity, that is, more latent heat flux change, in response to unit zonal surface wind change.

density $\left(1.2 \mathrm{~kg} \mathrm{~m}^{-3}\right)$. The vertical humidity gradient $\nabla q$ is written as

$$
\nabla q=q_{\mathrm{sat}}\left(T_{s}\right)-\mathrm{RH} \times q_{\mathrm{sat}}\left(T_{a}\right),
$$

where $q_{\text {sat }}(T)$ is the saturated specific humidity at temperature $T, \mathrm{RH}$ is relative humidity at the lowest model level, $T_{s}$ is surface temperature, and $T_{a}$ is air temperature at a reference height. Variable $\bar{w}$ is the wind speed calculated by

$$
\bar{w}=\sqrt{u^{2}+v^{2}+\hat{w}^{2}},
$$

where $u$ and $v$ are the monthly zonal and meridional components of surface wind and $\hat{w}$ is a background wind speed used to account for submonthly wind variance [set to $4 \mathrm{~m} \mathrm{~s}^{-1}$ as in Vimont et al. (2009)].

Conducting partial derivatives on Eq. (1), we can quantify the efficiency of the increase in convection and vertical humidity gradient on the change in latent heat flux:

$$
\delta \mathrm{LH}=\frac{\partial \mathrm{LH}}{\partial u} \delta u+\frac{\partial \mathrm{LH}}{\partial \nabla q} \delta \nabla q+\cdots,
$$


where $\partial \mathrm{LH} / \partial u$ is the zonal-wind coefficient to represent the sensitivity of latent heat flux to a change in unit zonal wind speed, while the change related to meridional wind is weak and ignored. The term $\partial \mathrm{LH} / \partial \nabla q$ is the moisture-gradient coefficient, showing the sensitivity to a unit change in sea-air surface specific humidity difference. If nonlinearity exists in the efficiency of the two response factors, a difference in either or both coefficients should emerge between + PMM and -PMM.

Using Eqs. (1) and (2), the zonal wind-coefficient can be written as

$$
\frac{\partial \mathrm{LH}}{\partial u}=-L_{v} C_{e} \rho_{a}\left[q_{\mathrm{sat}}\left(T_{s}\right)-\mathrm{RH} \times q_{\mathrm{sat}}\left(T_{\mathrm{ref}}\right)\right] \frac{u}{\bar{w}},
$$

indicating the combined effect of the vertical humidity gradient and surface wind speed (mostly zonal wind). Figures $8 \mathrm{c} 1-\mathrm{c} 5$ (left panels) show the patterns of difference in the zonal wind coefficient between +PMM and -PMM. From January to May, when the \pm PMM forcing is imposed, positive values appear along the pathway of the PMM southwestward propagation, meaning that the same amplitude anomalous zonal wind can result in stronger SST change in +PMM. Further decomposing the results in Figs. 10c1-c5, the differences related to the contrast of vertical humidity gradient and zonal wind in Eq. (5) are displayed in Figs. 10d1-d5 (center panels) and Figs. 10e1-e5 (right panels), respectively. It can be seen that the positive values of total difference are mostly contributed by those related to vertical humidity gradient. The pattern of the vertical humidity gradient-related difference resembles the monthly response of SST, showing the asymmetry of positive and negative PMM forcing. With warmer temperature, the zonal wind-latent heat flux link in the WES feedback is more efficient, which might be part of the reason for the stronger NCP SST warming in + PMM than the cooling in -PMM in our study. Note that the variables used for calculating the zonal wind coefficient (all lower panels in Fig. 10) are the transient monthly results in +PMM and -PMM, rather than the long-term monthly means that were used to evaluate the seasonal cycle of zonal wind coefficient in Vimont et al. (2009), since we focus on the difference in transient zonal wind coefficient.

Assuming that the wind speed is independent of $\nabla q$, the moisture gradient coefficient can be derived using

$$
\frac{\partial \mathrm{LH}}{\partial \nabla q}=-L_{v} C_{e} \rho_{a} \bar{w}
$$

Since the westerly wind anomaly reduces the total wind speed in + PMM while the easterly anomaly enhances it in - PMM, the moisture gradient coefficient is smaller in the former than in the latter, meaning that anomalous $\nabla q$ of equal magnitude plays a smaller damping effect in +PMM. However, it should be noted that positive temperature anomalies are suggested to result in larger $\delta \nabla q$ than negative anomalies of the same quantity (Zhang and McPhaden 1995). Therefore, the nonlinearity in the temperature-moisture damping effect may be ambiguous since the latent heat flux change is the product of $\partial \mathrm{LH} / \partial \nabla q$ and $\delta \nabla q$, implying that the nonlinearity in the convection-wind promotion effect may be more important.

\section{2) SDC RESPONSE}

A dramatic contrast in equatorial zonal surface winds also emerges during the boreal summer and autumn, when the SDC response connects the subtropics and tropics (Amaya et al. 2019). The monthly evolutions of the ITCZ from June to October in + PMM and - PMM are presented by total precipitation as shading in the lower left and middle panels of Fig. 11, respectively. The contours overlaid are the response of precipitation to PMM heat flux forcing, which is defined as the deviation from CTRL. The response pattern in +PMM is positive on the north and negative on the south, promoting the seasonal propagation of the ITCZ. On the other hand, the north negative and south positive response pattern in - PMM counteracts the northward shift of the ITCZ, which also limits the northward migration of the convection center. The difference in precipitation between $+\mathrm{PMM}$ and $-\mathrm{PMM}$ in the lower right panels of Fig. 11 shows a more evident contrast, displaying a distinct northward gradient from the western tropical Pacific to the central subtropical Pacific.

Figure 11a shows the monthly evolution of zonal surface wind index averaged over the central equatorial Pacific $\left(\mathrm{CP} ; 160^{\circ} \mathrm{E}-\right.$ $160^{\circ} \mathrm{W}, 5^{\circ} \mathrm{S}-5^{\circ} \mathrm{N}$; black-outlined box in Fig. 8c). Statistically significant difference in the CP zonal wind index between + PMM and - PMM occurs after June, which implies that the asymmetry of SDC responses of the zonal wind over the equator causes stronger warming in + PMM than cooling in - PMM. This contrast in Fig. 11a may also be related to the asymmetry in the WES feedback. In addition, compared to the pacemaker experiment results in Amaya et al. (2019), the response of precipitation in this study extends farther westward, which should be caused by the excessively westward extended bias that we have discussed in section $2 b$.

Overall, our results suggest that the main source of the asymmetric PMM influence on ENSO (Figs. 8, 9, and 11b) is the inherent asymmetry of the positive and negative PMM events. It develops during the PMM equatorward expansion due to different thermodynamic coupling strengths of the positive and negative PMM events, regulated by the climatological state of the trade wind-ITCZ complex in the northern tropical Pacific. This feature is different from the results of Thomas and Vimont (2016), who argued that the main reason for the nonlinearity of the impact of PMM on ENSO was the nonlinear SST response to thermocline anomalies.

\section{b. Amplification and damping roles of PMM for ENSO}

In this section, we first examine whether the influence of PMM on ENSO depends on the phases of ENSO. In the seasonal patterns, the strength and equatorward propagation of extratropical SST and zonal wind anomalies are similar between El Niño and La Niña events (Figs. 8a,b,e,f vs Figs. 9a,b,e,f). If we focus on the equatorial response, we can see the SST changes are also roughly comparable. Yet in detail, we can notice that the zonal center of equatorial SST response and the extent of the asymmetry show subtle differences. To quantitatively contrast the two, we show the response of Niño indices (Niño-4: $150^{\circ} \mathrm{E}-$ $150^{\circ} \mathrm{W}, 5^{\circ} \mathrm{S}-5^{\circ} \mathrm{N}$; Niño-3.4: $170^{\circ}-120^{\circ} \mathrm{W}, 5^{\circ} \mathrm{S}-5^{\circ} \mathrm{N}$; Niño-3: $150^{\circ}-$ $90^{\circ} \mathrm{W}, 5^{\circ} \mathrm{S}-5^{\circ} \mathrm{N}$ ) to the PMM heat flux forcing for $\mathrm{El} \mathrm{Niño} \mathrm{(red)}$ 
(a) $\mathrm{U}(\mathrm{CP})$

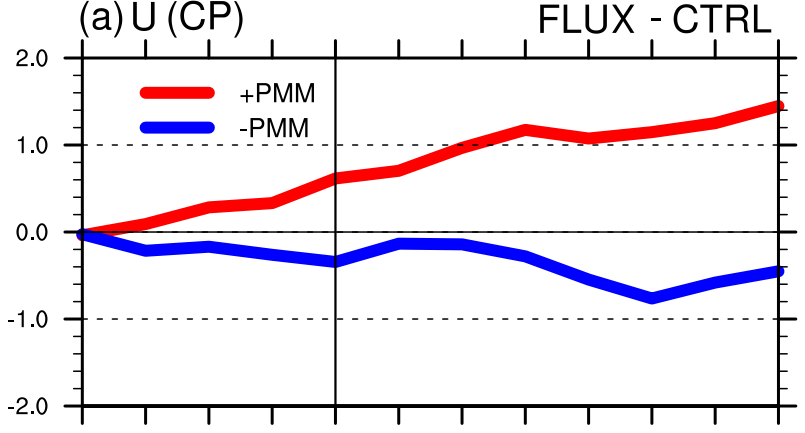

JAN FEB MAR APR MAY JUN JUL AUG SEP OCT NOV DEC (b) Nino3.4

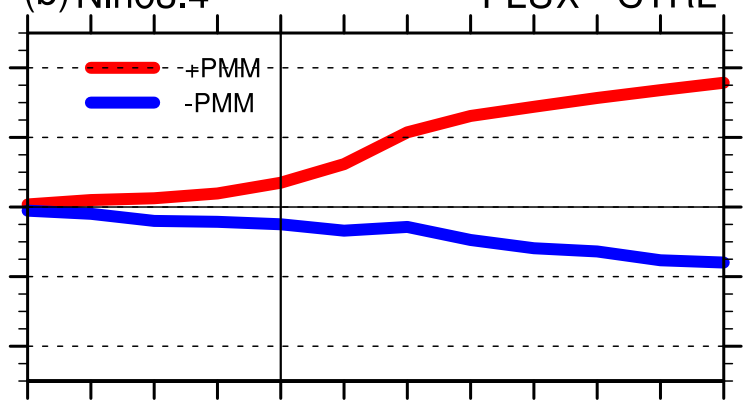

JAN FEB MAR APR MAY JUN JUL AUG SEP OCT NOV DEC
PRECIP(shading), FLUX-CTRL (contour)
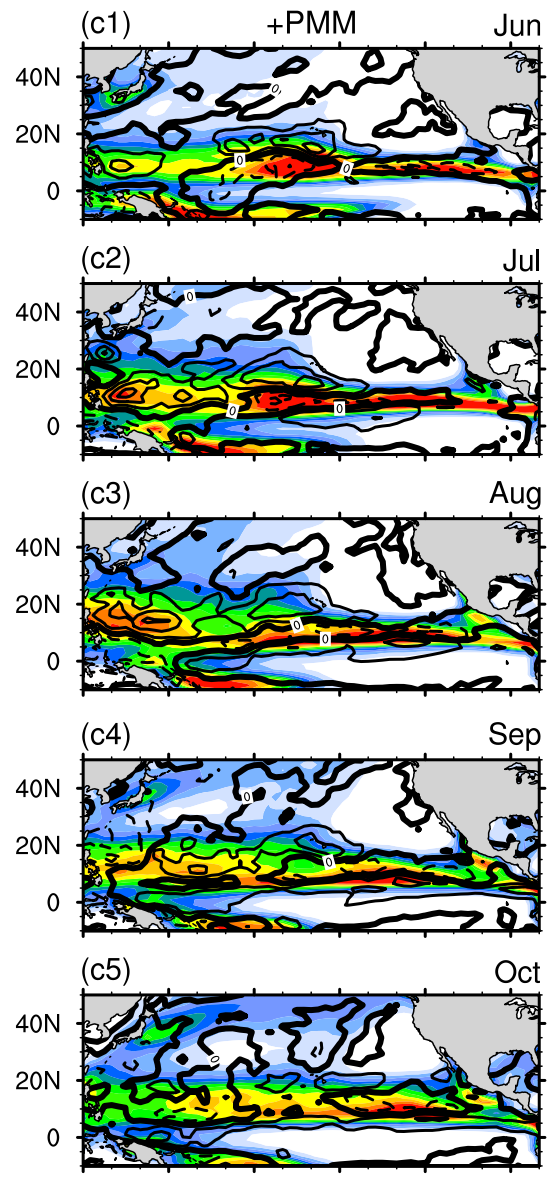

$120 \mathrm{E} \quad 150 \mathrm{E} \quad 180$ 150W 120W 90W

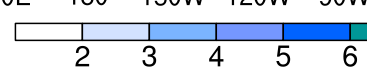

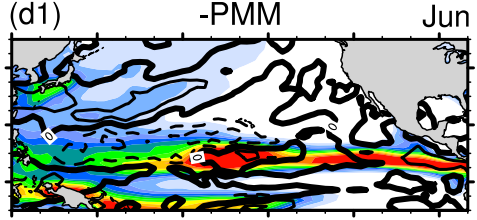
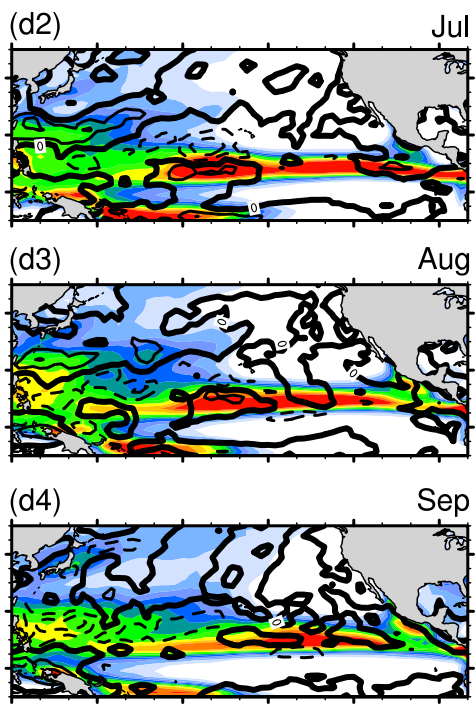

(d5)

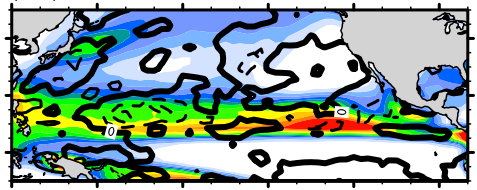

$120 \mathrm{E} \quad 150 \mathrm{E} \quad 180$ 150W 120W 90W

PRECIP_diff

(e1) +PMM minus -PMM Jun
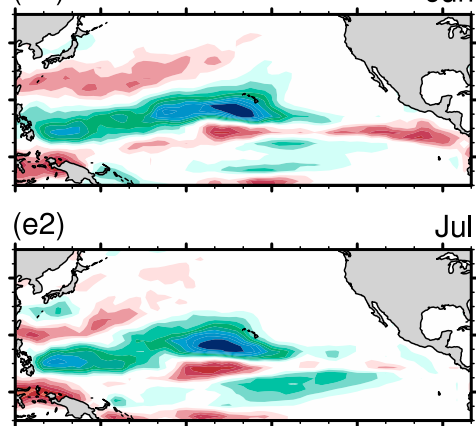

(e3) Aug
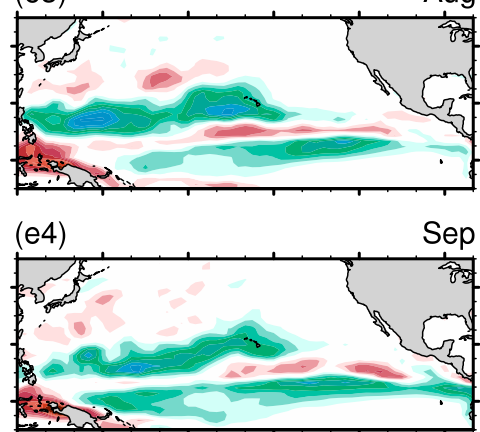

(e5)

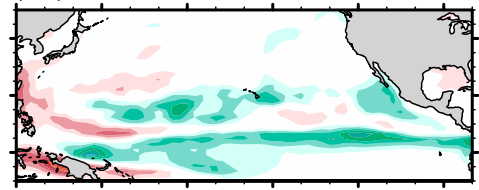

120E 150E 180 150W 120W 90W $\begin{array}{lllllllll}-4 & -3 & -2 & -1 & 0 & 1 & 2 & 3 & 4\end{array}$

CONTOUR FROM -5 TO 5 BY 1 unit $\mathrm{mm} /$ day

FIG. 11. The responses (+PMM/-PMM minus CTRL) of monthly (a) $\mathrm{CP}$ zonal wind index $\left(160^{\circ} \mathrm{E}-160^{\circ} \mathrm{W}, 5^{\circ} \mathrm{S}-5^{\circ} \mathrm{N}\right.$; black-outlined box in Fig. 8c) and (b) Niño-3.4 index to the PMM-related forcing. The red line is the averaged result of +PMM, and the blue line is the averaged result of -PMM. Also shown is the monthly evolution of precipitation (shading) and the response of precipitation (contours; $+\mathrm{PMM}$ - - PMM minus CTRL) in (left) + PMM and (right) - PMM, along with the difference in precipitation between + PMM and -PMM (+PMM minus -PMM), for (c1),(d1),(e1) June; (c2),(d2),(e2) July; (c3),(d3),(e3) August; (c4),(d4),(e4) September; and (c5),(d5),(e5) October. 
(a) Nino4

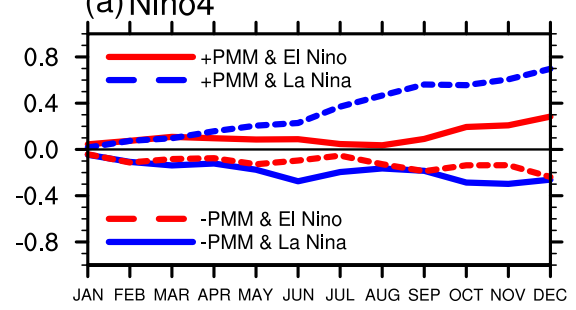

(b) Nino3.4

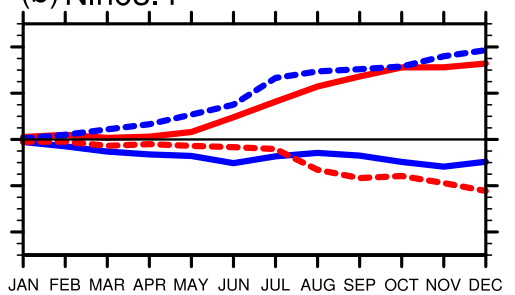

(c) Nino3

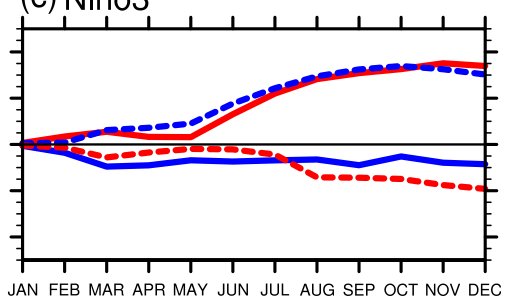

FIG. 12. The responses (+PMM/-PMM minus CTRL) of monthly (a) Niño-4, (b) Niño-3.4, and (c) Niño-3 indices to PMM-related forcing. Solid lines show the promotion effects (matched cases: positive PMM and El Niño, negative PMM and La Niña), and dashed lines show the damping effects (mismatched cases: positive PMM and La Niña, negative PMM and El Niño). The red lines are the composite results of El Niño events, and the blue lines are those of La Niña events.

and La Niña (blue) cases (Fig. 12). Interestingly, the El Niño composite response of Niño-4 is weak and that of Niño-3 is strong; in contrast, the La Niña composite response of Niño-4 is stronger and that of Niño-3 is relatively weaker. All these results indicate that the center of SST response is located in the eastern tropical Pacific for El Niño but in the western tropical Pacific for La Niña. Furthermore, the responses of the Niño indices confirm that the asymmetry between + PMM and - PMM is stronger, although not obviously so, for the La Niña composite results. In general, however, the asymmetry regarding the phases of ENSO should be much weaker than that between + PMM and - PMM.

Although the influence of PMM is only weakly sensitive to the phases of ENSO, the positive PMM, which exerts greater influence, plays an amplification role in the development of El Niño but a damping role for La Niña. On the contrary, the negative PMM makes a weaker contribution in damping El Niño and amplifying La Niña. As a result, the imposed PMM forcing leads to stronger SST changes in amplifying El Niño and damping La Niña (nearly $0.8^{\circ} \mathrm{C}$ for Niño-3.4; solid red and dashed blue lines in Fig. 12b) but induces weaker changes in amplifying La Niña and damping El Niño (less than $0.5^{\circ} \mathrm{C}$ for Niño-3.4; dashed red and solid blue lines in Fig. 12b). The different amplification effects seen here (solid lines in Fig. 12) may indicate that in spite of matched phases, a positive PMM event in spring is expected to be a good predictor for the occurrence of El Niño by the following winter, whereas a negative PMM event is not as counterpart for La Niña. This result is consistent with that of Larson and Kirtman (2014).

Previous studies focused on the amplification influence of PMM (e.g., Lu and Liu 2018) since the additive effects are more noticeably compared to the suppressing effects. However, as we can see from the dashed lines in Fig. 12, the damping effects of PMM on ENSO are nonnegligible and comparable to the amplification effects. Su et al. (2014) emphasized the damping role of a negative PMM event in 2012 and argued that it induced strong easterly anomalies over the central equatorial Pacific, inhibiting the potential SST warming in the eastern equatorial Pacific. Although the strong easterly wind bursts on the equator in the boreal summer of 2014 seemed capable of obstructing the expected "super" El Niño event predicted by most climate models (Hu and Fedorov 2016; Fan et al. 2019), the origin of these wind bursts is still being debated. Min et al. (2015) and Zhu et al. (2016) suggested that they were caused by the negative SST anomalies in the southeastern subtropical acific.

Moreover, the damping PMM forcing does not change the sign of the ensemble-mean Niño-3.4 index in our model results. For example, the Niño-3.4 changed by the positive PMM forcing for the two La Niña events is about $0.4^{\circ} \mathrm{C}$ in WLN and more than $1^{\circ} \mathrm{C}$ in SLN (Figs. 7c,d). However, the ensemblemean wintertime (December) Niño-3.4 index values in the $+\mathrm{PMM}$ cases of the two events are still negative $\left(-0.2^{\circ} \mathrm{C}\right.$ for WLN and $-0.3^{\circ} \mathrm{C}$ for SLN), although much weaker than the results in CTRL. Considering that the large-amplitude forcing that we applied is still unable to reverse the evolution of the ENSO, we suspect that the PMM mainly acts as a modulator, rather than a disruptor.

\section{Modulation of oceanic precondition and ENSO dynamics}

\section{a. Amplitude of ocean $\mathrm{HC}$}

According to ENSO theory, the accumulation and depletion of upper-ocean $\mathrm{HC}$ in the equatorial Pacific provide preconditions for the occurrence of ENSO events (Wyrtki 1985; Meinen and McPhaden 2001). Since the influence of the PMM on ENSO development can be regarded as a change in the tropical Pacific SST in response to extratropical atmospheric internal variability, its effectiveness may depend on the existing state of $\mathrm{HC}$ anomalies in the equatorial Pacific.

Figure 13 shows the upper-ocean HC anomalies in January of the four selected cases. Strong $\mathrm{HC}$ anomalies exist in the January of both SEN and SLN, though with opposite signs. On the other hand, the HC anomalies in the January of WEN and WLN are weaker, corresponding to the weak SST anomalies in the OND of these two cases. Based on the strength of $\mathrm{HC}$ anomalies, we use SEN and SLN to derive a strong-HC composite, and use WEN and WLN for a weak-HC composite. To identify the role of $\mathrm{HC}$, the seasonal response patterns of SST, surface wind, and upper-ocean $\mathrm{HC}$ in strong-HC and weakHC composites are displayed, respectively, in Figs. 14a-d and Figs. 14e-h. The imposed PMM forcing brings about comparable responses of extratropical SST and surface winds during JFM and AMJ in the strong-HC composite (Figs. 14a,b) and weak-HC composite (Figs. 14e,f). In JAS and OND, however, the ocean-atmosphere system over the equatorial Pacific shows 


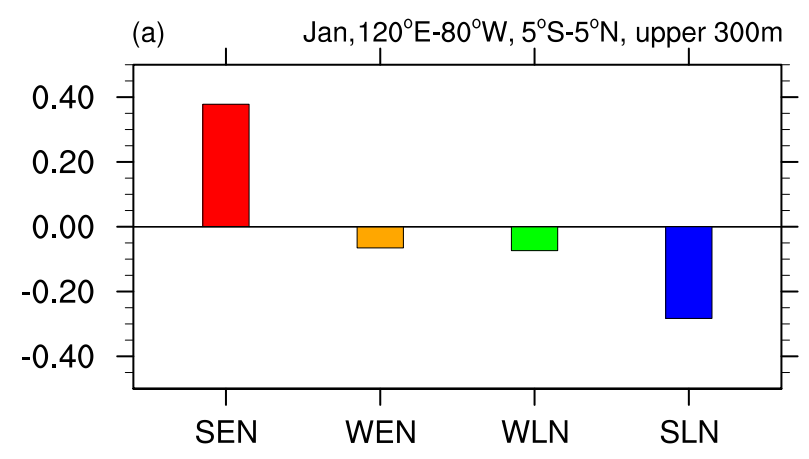

FIG. 13. Upper-ocean $\mathrm{HC}$ anomalies averaged over the equatorial Pacific Ocean $\left(120^{\circ} \mathrm{E}-80^{\circ} \mathrm{W}, 5^{\circ} \mathrm{S}-5^{\circ} \mathrm{N}\right)$ in January of selected cases.

different responses in the two composites. The SST in the eastern equatorial Pacific warms up gradually to more than $0.8^{\circ} \mathrm{C}$, with the strengthening response of zonal wind in strong-HC (Figs. 14c,d). As for weak-HC (Figs. 14g,h), the SST change in OND merely reaches $\sim 0.3^{\circ} \mathrm{C}$, much weaker than the response in strong-HC.

The subsurface evolution of equatorial Pacific gives more distinct evidence of the contrast. In CTRL of strong-HC (Figs. 15a1-a4), the subsurface warming in the central and eastern Pacific rises by more than $2.5^{\circ} \mathrm{C}$ at the beginning of the year, providing sufficient condition to generate great SST warming in the following season. For weak-HC, the subsurface warming in CTRL emerges from the central Pacific and then propagates to the eastern Pacific after AMJ (Figs. 15c1,c2). By the end of the year, the warming in CTRL of weak-HC is much weaker than that in CTRL of strong-HC (Figs. 15c3,c4) since the weaker equatorial $\mathrm{HC}$ anomalies limit the warming intensity. Aside from the distinction in CTRL, the subsurface temperature changes caused by PMM-related forcing show different intensities in strong-HC and weak-HC. In JFM and AMJ, before PMM-related zonal wind anomalies reach the equator, strong-HC and weak-HC show comparable warming of subsurface waters (Figs. 15b1,b2 and 15d1,d2). However, in JAS more distinct subsurface warming occurs in strong-HC (Figs. 15b3,d3). Ultimately, the warming in OND in strong-HC is about $2^{\circ} \mathrm{C}$ larger than that in weak-HC (Figs. 15b4,d4).

The different results between strong-HC and weak-HC are similar to the observed results of Park et al. (2013), which showed warmer subsurface temperature in the central equatorial Pacific in the NPO cases followed by El Niño events compared to the cases not followed by El Niño events. The greater efficiency in the strong-HC cases also reaffirms the finding in Anderson (2007), namely that anomalous low pressure in the northern subtropics is more effective in initiating the onset of El Niño events when preceded by positive $\mathrm{HC}$ in the western equatorial Pacific. In this case, the oceanic equatorial dynamics should be considered in the influence of PMM on the development of ENSO.

Moreover, by AMJ positive upper-ocean $\mathrm{HC}$ anomalies appear to the south of the off-equatorial southwesterly anomalies in both strong-HC and weak-HC composite results (Figs. 15b,f). This subsurface response reflects the dynamic effect of the PMM in charging or discharging $\mathrm{HC}$ of the equator and supporting the development of ENSO events, which was defined as "trade wind charging" (TWC; Anderson et al. 2013; Anderson and Perez 2015; Chakravorty et al. 2020). The TWC effect is also well demonstrated by the increased HC in FLUX shown in Figs. 15b1,b2 and 15d1,d2, which indicates that PMM-driven surface wind stress anomalies may contribute to the building/ dissipation of $\mathrm{HC}$ on the equator. However, it seems that the $\mathrm{HC}$ charging from the subtropics by the PMM shows similar amplitude in the strong-HC and weak-HC composite results. Therefore, the efficiency of PMM in modifying the development of ENSO events is more likely to depend on the preconditioning $\mathrm{HC}$ over the equator.

\section{b. Spread of ensemble members}

We noticed in Fig. 4 that the model spread of ENSO amplitudes in CTRL of each ensemble group is quite large. This indicates that ENSO may develop into different amplitudes with slightly perturbed initial conditions in spite of the same oceanic preconditioning. If large spread exists among ensemble members of each case in CTRL, whether the influences of the PMM differ between different ensemble members in each case deserves further examination. A follow-up question to address is what the relationship is between the spreads in CTRL and the spreads of the response in FLUX.

To answer these questions, we make a scatterplot of the December Niño-3.4 index of the ensemble members in CTRL versus the corresponding change in Niño-3.4 index in FLUX relative to CTRL for each ensemble run (Fig. 16). Interestingly, except for the +PMM of WEN, a significant negative relationship is displayed in the remaining seven ensemble runs. Taking El Niño cases as an example, positive PMM forcing induces greater promotion effect (warming) in the members that generate weaker warming in CTRL, but induces weaker promotion effect or even cooling in the members with stronger warming in CTRL. On the other hand, the damping effect of negative PMM forcing is weaker for the members that generate weaker warming in CTRL, but stronger for the members generating greater warming, and vice versa for the corresponding results of La Niña cases. This is partly in agreement with Alexander et al. (2010), which found that the response of equatorial SST to the NPO/PMM-related forcing depends on the expected ENSO amplitude in their control simulation. In short, the negative relationship here indicates that the influence of PMM on the amplitude of a particular ENSO event is limited to the range between the upper and lower bounds, which depend on the corresponding oceanic precondition. Combined with the discussion on the relationship between PMM and the initial state of $\mathrm{HC}$, this result further suggests that the PMM works as a modulator, rather than a disrupter or generator, for the development of the ENSO.

\section{Summary and discussion}

In this study, we carried out a series of sensitivity experiments with positive and also negative PMM-related heat flux forcing imposed in four typical ENSO cases to build up our understanding of PMM influence on ENSO evolution and 


\section{(+PMM minus -PMM)/2:}

\section{SST(shading:K), UV(vector:m/s), HC300(contour:K)}
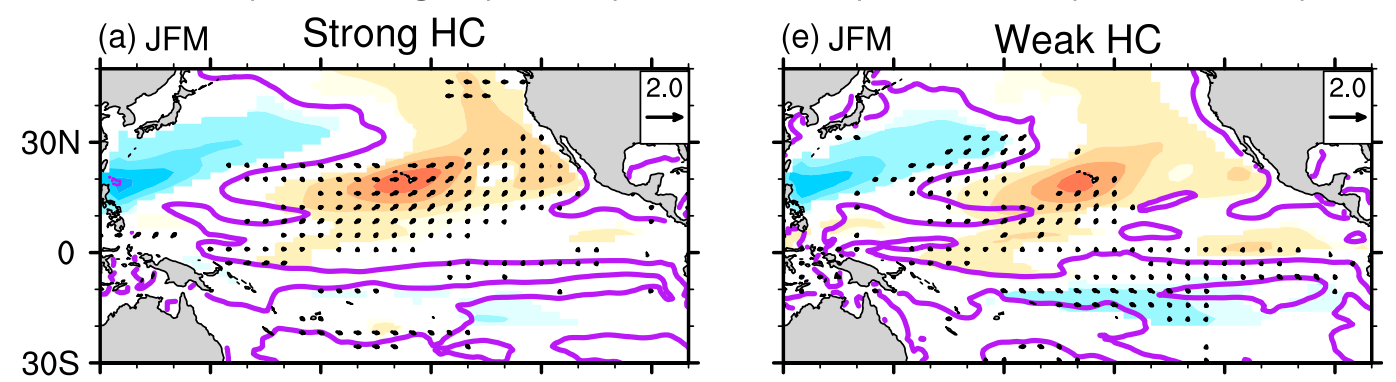

(b) AMJ

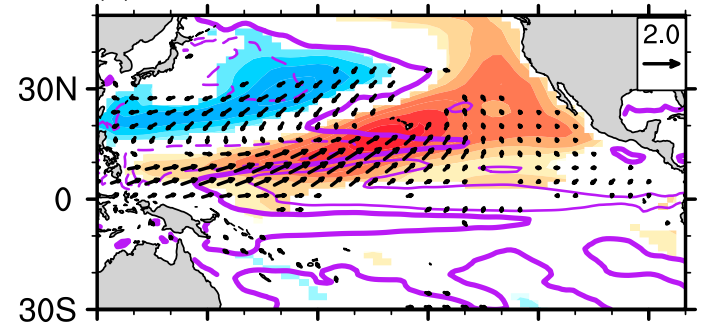

(f) $\mathrm{AMJ}$

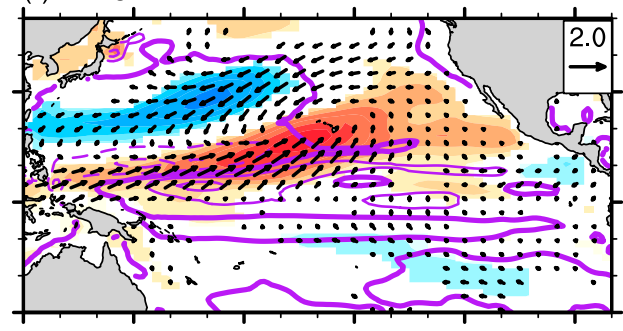

(c) JAS

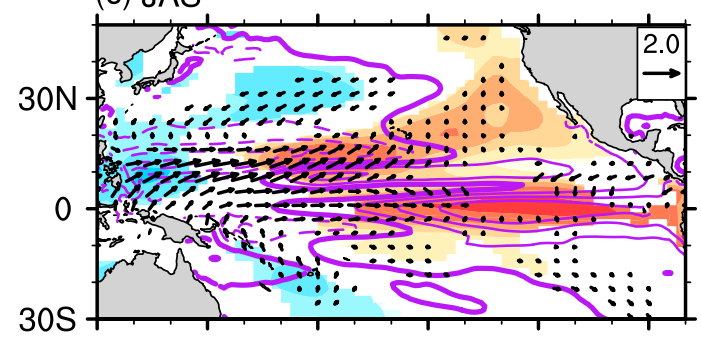

(g) JAS

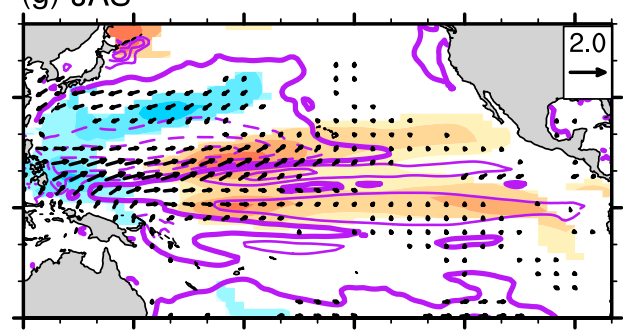

(d) OND

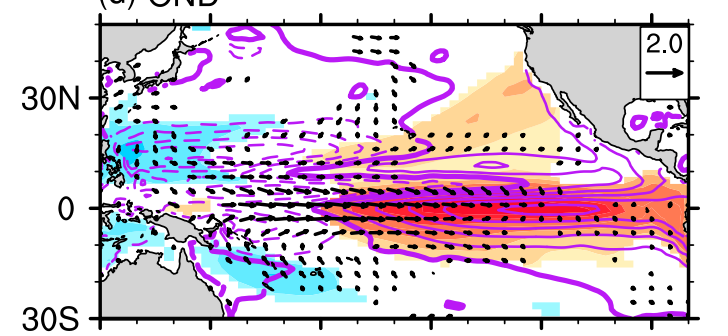

(h) OND

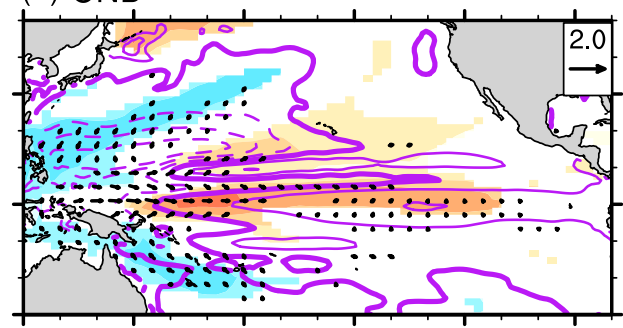

$120 \mathrm{E} \quad 150 \mathrm{E} \quad 180$ 150W 120W 90W

120E 150E 180 150W 120W 90W

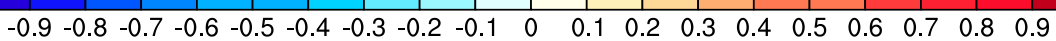

CONTOUR FROM -.9 TO $.9 \mathrm{BY} .15$

FIG. 14. Seasonal evolution of the responses of SST (shading; K), surface wind (vectors; $\mathrm{m} \mathrm{s}^{-1}$ ) and HC (contours; K) to PMM-related forcing., showing the averaged results of (a)-(d) strong-HC cases and (e)-(h) weak-HC cases. The reference vector is shown at the upper-right corner. Shading and vectors are shown only for the values that are statistically significant at the $95 \%$ confidence level on the basis of Student's $t$ test. The results shown are one-half of the differences between + PMM and -PMM.

predictability. With this modeling framework, we investigated the efficiency of PMM influence on ENSO, focusing on the asymmetry of positive and negative PMM, ENSO characteristics, and the modulation of ocean dynamics.
The imposed PMM forcing evokes SST changes and zonal surface wind anomalies in the subtropical Pacific, which further strengthen and gradually propagate to the tropics. When the PMM-induced signals reach the equatorial waveguide, the 


\section{Subsurface temperature(shading:K)}
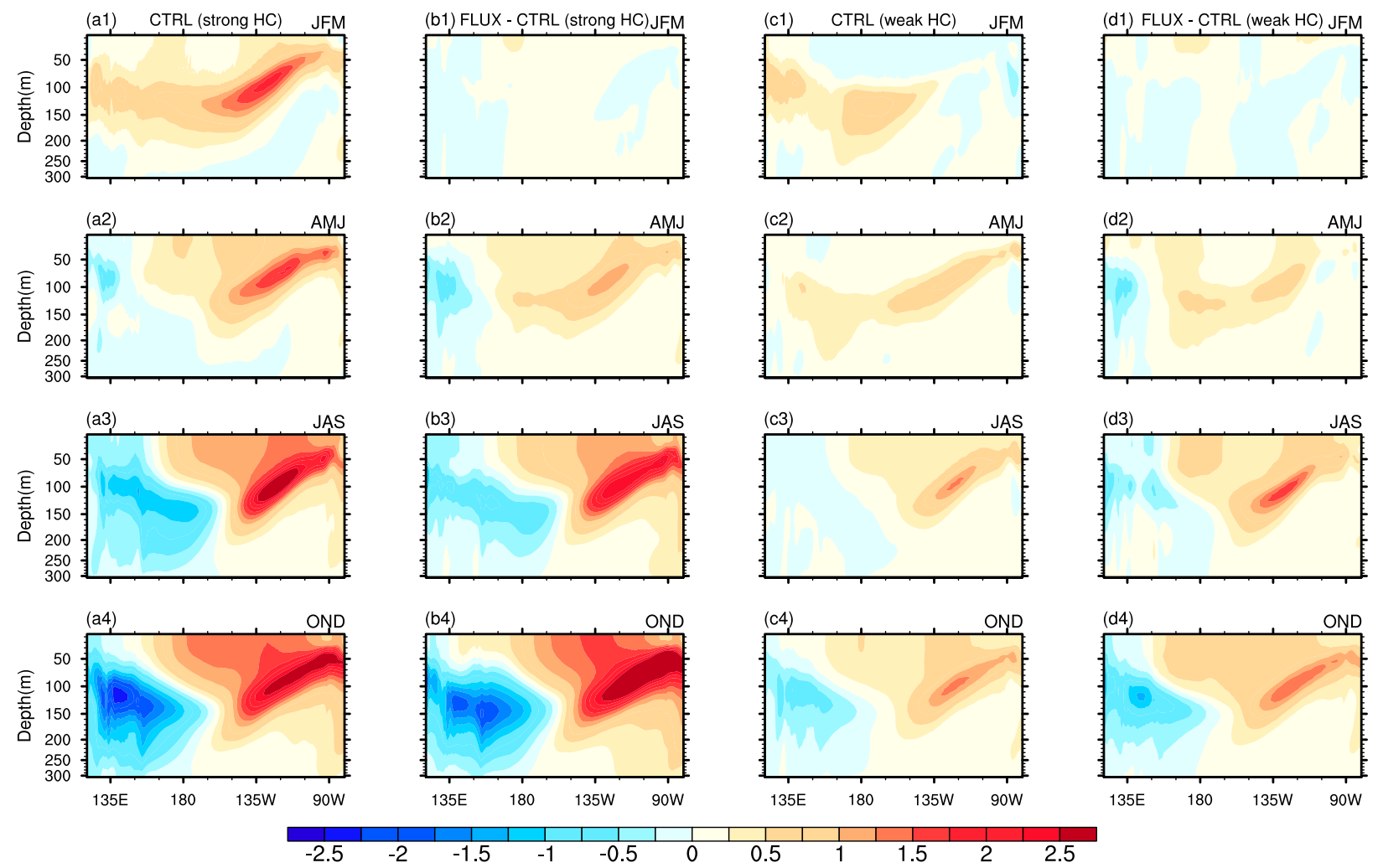

FIG. 15. Seasonal evolution of the depth-longitude section of subsurface temperature anomalies in CTRL (one-half of the composite of El Niño minus La Niña) of (a) strong-HC cases and (c) weak-HC cases, and the difference between FLUX and CTRL (one-half of + PMM minus - PMM) of (b) strong-HC cases and (d) weak-HC cases.

corresponding zonal wind anomalies trigger an ocean-atmosphere dynamic feedback process, which changes the SST in the centraleastern equatorial Pacific and reinforces or damps ENSO evolution.

In comparison with previous studies, the novel aspect of this work is to examine PMM influences on the evolution of individual ENSO events by including the process of the PMM itself, which evolves from an extratropical phenomenon to a tropical phenomenon. It is found that the asymmetry between positive and negative PMM events plays an important role in their different efficiencies of influencing ENSO. Despite originating from equal extratropical sources, the positive PMM events generally grow stronger than the negative ones in the subtropics because positive PMM events evoke stronger changes in subtropical SST. This is partly due to a larger transient growth rate of latent heat flux in the WES feedback during positive PMM events. The other reason is the more northward migration of the ITCZ in the boreal summer and fall, which allows the WES-induced subtropical SST anomalies to induce stronger deep convection in the ITCZ and thus further convey the wind perturbations to the equatorial Pacific. Our results reveal a different aspect of PMM influence on the ENSO compared to that discussed in Thomas and Vimont (2016); we show the asymmetry due to the nonlinear response of SST to the PMM-induced thermocline depth anomalies. Overall, PMM forcing matched to ENSO [i.e., a positive (negative) PMM prior to an El Niño (a La Niña)] plays an enhancing role while a mismatched PMM forcing plays a damping role. For the matched cases, a positive PMM event enhances an El Niño more strongly than a negative PMM event enhances a La Niña.

Unlike the nearly exclusive focus on the amplification effect of the PMM in many previous studies, we also examine the potential damping effect of the PMM. In our experiments, the damping effect is stronger than the promotion effect and thus nonnegligible in the development of ENSO. This damping effect has practical significance as shown by the discussion of the false alarms to the strong El Niño predictions in 2012 (Su et al. 2014) and 2014 (Min et al. 2015). However, we notice that the strong PMM forcing that we applied does not reverse the sign of ensemble-mean SST anomalies even for the cases with weaker ENSO amplitudes in CTRL. Therefore, the PMM should be considered as a modulator, instead of a major generator, in ENSO prediction.

Although the PMM can be seen as an external noise for the development of the ENSO, it is more effective than the typical weather noise because the coupled WES feedback in 


\section{Spread of ensemble members}
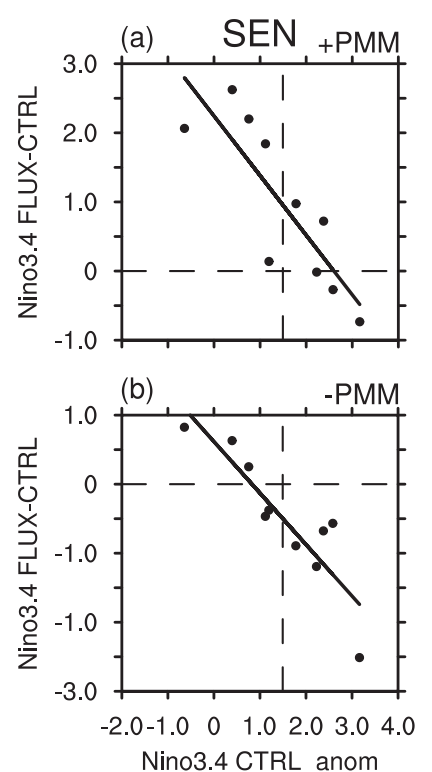
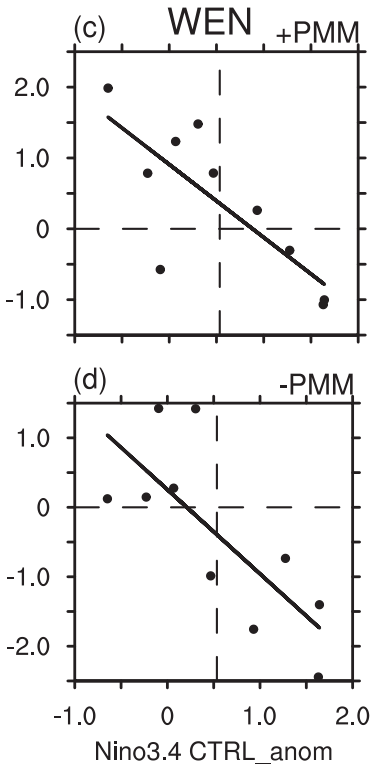
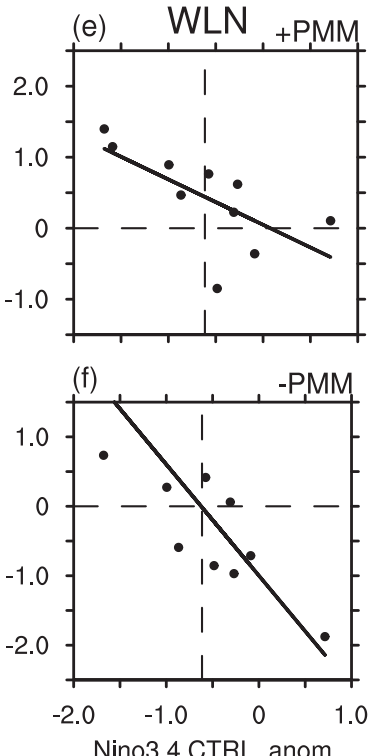
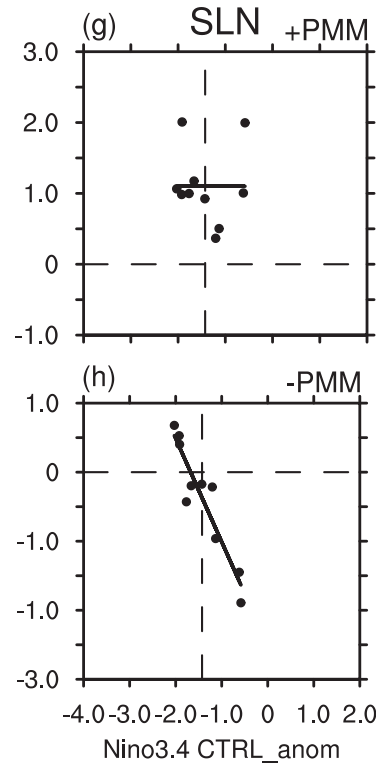

FIG. 16. Scatterplots of Niño-3.4 index in CTRL and the difference between FLUX and CTRL (+PMM/-PMM minus CTRL) for eight groups of ensemble runs ( \pm PMM of four cases). Dots are ensemble members, black oblique lines are the regression lines, the horizontal dashed line is the zero line, and the vertical dashed line denotes the averaged value in CTRL.

the subtropics prolongs its persistence. Furthermore, the efficiency of PMM influence is modulated by the coupled equatorial ocean-atmosphere dynamics, including the large inertia of the oceanic memory. In fact, greater responses of equatorial SST are found in the cases with stronger preexisting $\mathrm{HC}$, and vice versa for the cases with weaker HC. It is also found that the PMM can charge or discharge the $\mathrm{HC}$ of the equator via the TWC mechanism and then contribute to the development of ENSO events. Yet, it seems that the contribution of the TWC is not sensitive to the preconditioning $\mathrm{HC}$ on the equator.

We also find that the spreads in CTRL and FLUX experiments are quite large and that a negative relationship exists between the December Niño-3.4 in CTRL and the corresponding change in FLUX relative to the CTRL in each case. This result implies that the influence of PMM on a particular ENSO event is limited by the corresponding oceanic precondition, which further suggests role of the PMM as a modulator, rather than a disrupter or generator.

Our results demonstrate the necessity of applying PMM as a reference in ENSO prediction. At the same time, we show that understanding the nonlinearity of PMM forcing and its relationship with oceanic precondition would help appropriately recognize the PMM as a predictor. Still, we have not demonstrated that the PMM is a generator of ENSO events because all the cases that we studied have certain $\mathrm{HC}$ preconditioning and none of them can be considered as noisedriven. It should also be noted that some uncertainties might exist due to the subjective choices of the amplitude of PMMrelated forcing and the strong or weak El Niño/La Niña events used in the study. In this sense, cleanly isolating the effect of PMM in model simulations is our next step to further understand to what extent the triggering role of PMM is valid and what strength and characters of the noise-driven ENSO can be achieved.

Moreover, we limit our scope to the meridional influence on the ENSO from the north. Recently, several studies suggested that the South Pacific meridional mode (SPMM) is also important for the development and prediction uncertainty of ENSO (Zhang et al. 2014; Min et al. 2017; Larson et al. 2018). Therefore, it is also worthwhile to study the SPMM influence in the same framework discussed here in our future investigation. Last but not least, it is necessary to further work on the effects from other oceanic basins outside the Pacific (e.g., Park et al. 2019) and the low-frequency variability of the PMM itself (Yeh et al. 2018), which can also modulate the PMM-ENSO relationship but have not been explored in this study.

Acknowledgments. The authors thank the three anonymous reviewers who provided useful comments for improving the overall quality of the paper. This study was partially supported by the National Key Research and Development Program of China (2016YFA0602703), the National Natural Science Foundation of China (Grants 42088101, 41690123, and 41690120), the Jiangsu Collaborative Innovation Center for Climate Change, and Guangdong Province Key Laboratory for Climate Change and Natural Disaster Studies (Grant 2020B1212060025). Bohua Huang was supported by the NOAA MAPP drought project (NA17OAR4310144). All figures in this study were generated by the NCAR Command Language (version 6.5.0; https://doi.org/10.5065/D6WD3XH5). 


\section{REFERENCES}

Alexander, M. A., D. J. Vimont, P. Chang, and J. D. Scott, 2010: The impact of extratropical atmospheric variability on ENSO: Testing the seasonal footprinting mechanism using coupled model experiments. J. Climate, 23, 2885-2901, https://doi.org/ 10.1175/2010JCLI3205.1.

Amaya, D. J., 2019: The Pacific meridional mode and ENSO: A review. Curr. Climate Change Rep., 5, 296-307, https://doi.org/ 10.1007/s40641-019-00142-x.

—, Y. Kosaka, W. Zhou, Y. Zhang, S.-P. Xie, and A. J. Miller, 2019: The North Pacific pacemaker effect on historical ENSO and its mechanisms. J. Climate, 32, 7643-7661, https://doi.org/ 10.1175/JCLI-D-19-0040.1.

Anderson, B. T., 2007: On the joint role of subtropical atmospheric variability and equatorial subsurface heat content anomalies in initiating the onset of ENSO events. J. Climate, 20, 15931599, https://doi.org/10.1175/JCLI4075.1.

—, and R. C. Perez, 2015: ENSO and non-ENSO induced charging and discharging of the equatorial Pacific. Climate Dyn., 45, 2309-2327, https://doi.org/10.1007/s00382-015-2472-x.

,-- , and A. Karspeck, 2013: Triggering of El Niño onset through trade wind-induced charging of the equatorial Pacific. Geophys. Res. Lett., 40, 1212-1216, https://doi.org/10.1002/ $\operatorname{grl} .50200$.

Busalacchi, A. J., and M. A. Cane, 1988: The effect of varying stratification on low-frequency equatorial motions. J. Phys. Oceanogr., 18, 801-812, https://doi.org/10.1175/1520-0485(1988) 018<0801:TEOVSO $>2.0$. CO;2.

Capotondi, A., and P. D. Sardeshmukh, 2015: Optimal precursors of different types of ENSO events. Geophys. Res. Lett., 42, 9952-9960, https://doi.org/10.1002/2015GL066171.

Chakravorty, S., R. C. Perez, B. T. Anderson, B. S. Giese, S. M. Larson, and V. Pivotti, 2020: Testing the trade wind charging mechanism and its influence on ENSO variability. J. Climate, 33, 7391-7411, https://doi.org/10.1175/JCLI-D-19-0727.1.

Chang, P., L. Ji, and H. Li, 1997: A decadal climate variation in the tropical Atlantic Ocean from thermodynamic air-sea interactions. Nature, 385, 516-518, https://doi.org/10.1038/385516a0.

—, L. Zhang, R. Saravanan, D. J. Vimont, J. C. H. Chiang, L. Ji, H. Seidel, and M. K. Tippett, 2007: Pacific meridional mode and El Niño-Southern Oscillation. Geophys. Res. Lett., 34, L16608, https://doi.org/10.1029/2007GL030302.

Chiang, J. C. H., and D. J. Vimont, 2004: Analogous Pacific and Atlantic meridional modes of tropical atmosphere-ocean variability. J. Climate, 17, 4143-4158, https://doi.org/10.1175/ JCLI4953.1.

Deser, C., and Coauthors, 2012: ENSO and Pacific decadal variability in the Community Climate System Model version 4. J. Climate, 25, 2622-2651, https://doi.org/10.1175/JCLI-D-11-00301.1.

Dewitte, B., S. Purca, S. Illig, L. Renault, and B. S. Giese, 2008: Low-frequency modulation of intraseasonal equatorial Kelvin wave activity in the Pacific from SODA: 1958-2001. J. Climate, 21, 6060-6069, https://doi.org/10.1175/2008JCLI2277.1.

Fan, H., B. Huang, S. Yang, Z. Li, and K. Deng, 2019: Seasonallydependent impact of easterly wind bursts on the development of El Niño events. Climate Dyn., 53, 1527-1546, https://doi.org/ 10.1007/s00382-019-04688-2.

Hu, S., and A. V. Fedorov, 2016: Exceptionally strong easterly wind burst stalling El Niño of 2014. Proc. Natl. Acad. Sci. USA, 113, 2005-2010, https://doi.org/10.1073/pnas.1514182113.

Huang, B., and J. Shukla, 2005: Ocean-atmosphere interactions in the tropical and subtropical Atlantic Ocean. J. Climate, 18, 1652-1672, https://doi.org/10.1175/JCLI3368.1.
Hurrell, J. W., and Coauthors, 2013: The Community Earth System Model: A framework for collaborative research. Bull. Amer. Meteor. Soc., 94, 1339-1360, https://doi.org/10.1175/BAMS-D-1200121.1.

Jin, F.-F., 1997: An equatorial ocean recharge paradigm for ENSO. Part I: Conceptual model. J. Atmos. Sci., 54, 811-829, https:// doi.org/10.1175/1520-0469(1997)054<0811:AEORPF>2.0.CO;2.

Kao, H.-Y., and J.-Y. Yu, 2009: Contrasting eastern-Pacific and central-Pacific types of ENSO. J. Climate, 22, 615-632, https:// doi.org/10.1175/2008JCLI2309.1.

Kutzbach, J. E., 1970: Large-scale features of monthly mean Northern Hemisphere anomaly maps of sea-level pressure. Mon. Wea. Rev., 98, 708-716, https://doi.org/10.1175/15200493(1970)098<0708:LSFOMM >2.3.CO;2.

Larson, S. M., and B. P. Kirtman, 2014: The Pacific meridional mode as an ENSO precursor and predictor in the North American Multimodel Ensemble. J. Climate, 27, 7018-7032, https://doi.org/10.1175/JCLI-D-14-00055.1.

— K. V. Pegion, and B. P. Kirtman, 2018: The South Pacific meridional mode as a thermally driven source of ENSO amplitude modulation and uncertainty. J. Climate, 31, 5127-5145, https://doi.org/10.1175/JCLI-D-17-0722.1.

Lin, C.-Y., J.-Y. Yu, and H.-H. Hsu, 2015: CMIP5 model simulations of the Pacific meridional mode and its connection to the two types of ENSO. Int. J. Climatol., 35, 2352-2358, https:// doi.org/10.1002/joc.4130.

Lindzen, R. S., and S. Nigam, 1987: On the role of sea surface temperature gradients in forcing low-level winds and convergence in the tropics. J. Atmos. Sci., 44, 2418-2436, https:// doi.org/10.1175/1520-0469(1987)044<2418:OTROSS $>2.0$. $\mathrm{CO} ; 2$.

Linkin, M. E., and S. Nigam, 2008: The North Pacific Oscillationwest Pacific teleconnection pattern: Mature-phase structure and winter impacts. J. Climate, 21, 1979-1997, https://doi.org/ 10.1175/2007JCLI2048.1.

Lu, F., and Z. Liu, 2018: Assessing extratropical influence on observed El Niño-Southern Oscillation events using regional coupled data assimilation. J. Climate, 31, 8961-8969, https:// doi.org/10.1175/JCLI-D-17-0849.1.

_ _ - Y. Yiu, S. Zhang, and R. Jacob, 2017: Understanding the control of extratropical atmospheric variability on ENSO using a coupled data assimilation approach. Climate Dyn., 48, 3139-3160, https://doi.org/10.1007/s00382-016-3256-7.

Ma, J., S. P. Xie, and H. Xu, 2017: Contributions of the North Pacific meridional mode to ensemble spread of ENSO prediction. J. Climate, 30, 9167-9181, https://doi.org/10.1175/ JCLI-D-17-0182.1.

Meinen, C. S., and M. J. McPhaden, 2001: Interannual variability in warm water volume transports in the equatorial Pacific during 1993-99. J. Phys. Oceanogr., 31, 1324-1345, https://doi.org/ 10.1175/1520-0485(2001)031<1324:IVIWWV>2.0.CO;2.

Min, Q., J. Su, R. Zhang, and X. Rong, 2015: What hindered the El Niño pattern in 2014? Geophys. Res. Lett., 42, 6762-6770, https://doi.org/10.1002/2015GL064899.

,-- , and - 2017: Impact of the South and North Pacific meridional modes on El Niño-Southern Oscillation: Observational analysis and comparison. J. Climate, 30, 1705-1720, https://doi.org/ 10.1175/JCLI-D-16-0063.1.

Newman, M., and P. D. Sardeshmukh, 1995: A caveat concerning singular value decomposition. J. Climate, 8, 352-360, https:// doi.org/10.1175/1520-0442(1995)008<0352:ACCSVD>2.0.CO;2.

Park, J.-H., T. Li, S.-W. Yeh, and H. Kim, 2019: Effect of recent Atlantic warming in strengthening Atlantic-Pacific teleconnection 
on interannual timescale via enhanced connection with the Pacific meridional mode. Climate Dyn., 53, 371-387, https://doi.org/ 10.1007/s00382-018-4591-7.

Park, J.-Y., S.-W. Yeh, J.-S. Kug, and J. Yoon, 2013: Favorable connections between seasonal footprinting mechanism and El Niño. Climate Dyn., 40, 1169-1181, https://doi.org/10.1007/ s00382-012-1477-y.

Rogers, J. C., 1981: The North Pacific Oscillation. J. Climatol., 1, 39-57, https://doi.org/10.1002/joc.3370010106.

Schopf, P. S., and D. E. Harrison, 1983: On equatorial waves and El Niño. I. Influence of initial states on wave-induced currents and warming. J. Phys. Oceanogr., 13, 936-948, https://doi.org/ 10.1175/1520-0485(1983)013<0936:OEWAEN > 2.0.CO;2.

Su, J., B. Xiang, B. Wang, and T. Li, 2014: Abrupt termination of the 2012 Pacific warming and its implication on ENSO prediction. Geophys. Res. Lett., 41, 9058-9064, https://doi.org/ 10.1002/2014GL062380.

Thomas, E. E., and D. J. Vimont, 2016: Modeling the mechanisms of linear and nonlinear ENSO responses to the Pacific meridional mode. J. Climate, 29, 8745-8761, https://doi.org/ 10.1175/JCLI-D-16-0090.1.

Vimont, D. J., D. S. Battisti, and A. C. Hirst, 2001: Footprinting: A seasonal connection between the tropics and mid-latitudes. Geophys. Res. Lett., 28, 3923-3926, https://doi.org/10.1029/2001GL013435.

,$- \ldots$, and $—, 2003 \mathrm{a}$ : The seasonal footprinting mechanism in the CSIRO general circulation models. J. Climate, 16, 2653-2667, https://doi.org/10.1175/1520-0442(2003)016<2653: TSFMIT $>2.0 . \mathrm{CO} ; 2$.

_ J. M. Wallace, and D. S. Battisti, 2003b: The seasonal footprinting mechanism in the Pacific: Implications for ENSO. J. Climate, 16, 2668-2675, https://doi.org/10.1175/1520-0442(2003)016<2668: TSFMIT $>2.0$.CO;2.

—, M. Alexander, and A. Fontaine, 2009: Midlatitude excitation of tropical variability in the Pacific: The role of thermodynamic coupling and seasonality. J. Climate, 22, 518-534, https://doi.org/10.1175/2008JCLI2220.1.

Walker, G. T., and E. W. Bliss, 1932: World weather V. Mem. Roy. Meteor. Soc., 4, 53-84.
Wallace, J. M., and D. S. Gutzler, 1981: Teleconnections in the geopotential height field during the Northern Hemisphere winter. Mon. Wea. Rev., 109, 784-812, https://doi.org/10.1175/ 1520-0493(1981)109<0784:TITGHF>2.0.CO;2.

Wang, X., M. Chen, C. Wang, S. W. Yeh, and W. Tan, 2019: Evaluation of performance of CMIP5 models in simulating the North Pacific Oscillation and El Niño Modoki. Climate Dyn., 52, 1383-1394, https://doi.org/10.1007/s00382-0184196-1.

Wyrtki, K., 1985: Water displacements in the Pacific and the genesis of El Niño cycles. J. Geophys. Res., 90, 7129, https:// doi.org/10.1029/JC090iC04p07129.

Xie, S., and S. G. H. Philander, 1994: A coupled ocean-atmosphere model of relevance to the ITCZ in the eastern Pacific. Tellus, 46A, 340-350, https://doi.org/10.3402/tellusa.v46i4.15484.

Yeh, S. W., D. W. Yi, M. K. Sung, and Y. H. Kim, 2018: An eastward shift of the North Pacific Oscillation after the mid-1990s and its relationship with ENSO. Geophys. Res. Lett., 45, 66546660, https://doi.org/10.1029/2018GL078671.

Yu, J.-Y., P. Kao, H. Paek, H.-H. Hsu, C. Hung, M.-M. Lu, and S.-I. An, 2015: Linking emergence of the central Pacific El Niño to the Atlantic multidecadal oscillation. J. Climate, 28, 651-662, https://doi.org/10.1175/JCLI-D-14-00347.1.

Zhang, G. J., and M. J. McPhaden, 1995: The relationship between sea surface temperature and latent heat flux in the equatorial Pacific. J. Climate, 8, 589-605, https://doi.org/10.1175/15200442(1995)008<0589:TRBSST $>2.0$. CO;2.

Zhang, H., A. Clement, and P. Di Nezio, 2014: The South Pacific meridional mode: A mechanism for ENSO-like variability. J. Climate, 27, 769-783, https://doi.org/10.1175/JCLI-D-1300082.1.

Zhang, L., P. Chang, and L. Ji, 2009: Linking the Pacific meridional mode to ENSO: Coupled model analysis. J. Climate, 22, 34883505, https://doi.org/10.1175/2008JCLI2473.1.

Zhu, J., A. Kumar, B. Huang, M. A. Balmaseda, Z. Z. Hu, L. Marx, and J. L. Kinter, 2016: The role of off-equatorial surface temperature anomalies in the $2014 \mathrm{El}$ Niño prediction. Sci. Rep., 6, 19677, https://doi.org/10.1038/srep19677. 